\title{
Towards improving the simulation of meteorological fields in urban areas through updated/advanced surface fluxes description
}

\author{
A. Baklanov ${ }^{1}$, P. G. Mestayer ${ }^{2}$, A. Clappier ${ }^{3}$, S. Zilitinkevich ${ }^{4}$, S. Joffre ${ }^{5}$, A. Mahura ${ }^{1,2}$, and N. W. Nielsen ${ }^{1}$ \\ ${ }^{1}$ Meteorological Research Department, Danish Meteorological Institute, DMI, Copenhagen, Denmark \\ ${ }^{2}$ Laboratoire de Mécanique des Fluides, UMR CNRS 6598, Ecole Centrale de Nantes, ECN, France \\ ${ }^{3}$ La section Sciences et Ingénierie de l'Environnement (SSIE), Ecole Polytechnique Fédérale de Lausanne, EPFL, Switzerland \\ ${ }^{4}$ Division of Atmospheric Sciences, University of Helsinki, Finland \\ ${ }^{5}$ Research \& Development, Finnish Meteorological Institute, FMI, Helsinki, Finland
}

Received: 1 September 2005 - Published in Atmos. Chem. Phys. Discuss.: 24 November 2005

Revised: 3 December 2007 - Accepted: 7 January 2008 - Published: 6 February 2008

\begin{abstract}
The increased resolution of numerical weather prediction models allows nowadays addressing more realistically urban meteorology and air pollution processes. This has triggered new interest in modelling and describing experimentally the specific features and processes of urban areas. Recent developments and results performed within the EU-funded project FUMAPEX on integrated systems for forecasting urban meteorology and air pollution are reported here. Sensitivity studies with respect to optimum resolution, parametrisation of urban roughness and surface exchange fluxes and the role of urban soil layers are carried out with advanced meso- or sub-meso meteorological models. They show that sensible improvements can be achieved by higher model resolution that is accompanied with better description of urban surface features. Recommendations, especially with respect to advanced urban air quality forecasting and information systems, are given together with an assessment of the needed further research and data.
\end{abstract}

\section{Introduction}

During the last decade, substantial progresses in both mesometeorological and numerical weather prediction (NWP) modelling and the description of urban atmospheric processes have been achieved. For instance, state-of-the-art nested NWP models can use land-use databases down to $1 \mathrm{~km}$ resolution or finer, enabling to provide high quality urban meteorological data. Thus, NWP models are now approaching the necessary horizontal and vertical resolution to provide weather forecasts for the urban scale (e.g. Baklanov et al., 2002).

Correspondence to: A. Baklanov

(alb@dmi.dk)
Many urban features can influence the atmospheric flow, its turbulence regime, the microclimate (Oke, 1978), and, accordingly modify the transport, dispersion, and deposition of atmospheric pollutants within urban areas, namely:

- Local-scale heterogeneities, such as sharp changes of roughness and heat fluxes;

- Sheltering effects of buildings on the wind-velocity;

- Redistribution of eddies, from large to small, due to buildings;

- Trapping of radiation in street canyons;

- Urban soil structure and covering materials,

- Different diffusivities of heat and water vapour in the canopy layer;

- Anthropogenic heat fluxes;

- Urban internal boundary layers and the urban mixing height;

- Pollutants (including aerosols) retroaction on urban meteorology and climate;

- Urban perturbation of clouds and precipitation.

Despite the increased resolution and various improvements, current operational NWP models still have several shortcomings with respect to urban areas, such as:

- Urban areas are mostly described by similar subsurface, surface, and boundary layer formulations as rural areas.

Published by Copernicus Publications on behalf of the European Geosciences Union. 
- These formulations do not account for specific urban dynamics and energetics or for their impacts on the simulation of the atmospheric urban boundary layer (UBL) and its intrinsic characteristics (e.g. internal boundary layers, urban heat islands, precipitation patterns).

- Additionally, NWP models are not primarily developed for air pollution and emergency modelling, and their outputs need to be designed as suitable input for such urban-scale models.

Nevertheless, in recent years, a number of parameterisation schemes have been developed to estimate the components of the surface energy balance (SEB) (net radiation and heat fluxes) and other UBL parameters. For instance, the COST-715 Action (Fisher et al., 2005, 2006; Piringer and Joffre, 2005) reviewed several approaches for the specific treatment of UBL features and SEB.

A palette of urban SEB schemes and models are now available (e.g., Oke et al., 1999; Grimmond and Oke, 1999a; Masson, 2000; Dupont, 2001; Martilli et al., 2002). However, they have not all been validated to the same degree and they have not been applied and classified for different scales and types of models (e.g., research meso-meteorological, NWP, urban air quality assessment and forecasting). They range from simple transformations of some key coefficients in exchange schemes developed for natural surfaces to detailed modules computing quasi-explicitly the radiative and turbulent energy exchanges of each built element category, e.g., the ground surface, walls and roofs, treated in group by type. Furthermore, even more detailed models and software are available to compute the thermo-radiative budgets of, or interactions with, elemental building surfaces. These tools may be used to analyse experimental data from validation campaigns, to run numerical experiments for urban areas, or to perform sensitivity analysis studies.

Better insight into SEB terms for developing parametrisation schemes were also brought up through rather recent experimental studies such as: SOLENE (Groleau et al., 2003), POV RAY (Lagouarde et al., 2002), DART (GastelluEtchegorry et al., 2004), and SSS (Soux et al., 2004).

The development and validation of these SEB models brought to light and helped to quantify several specificities of the urban canopy energetics:

- Net radiation varies in time at the local scale with solar orientation and in space with district morphology, which is not much different from its rural counterpart on average;

- The diurnal cycle of the turbulent sensible heat flux is large but highly variable, strongly dependent on district structure, and often positive at night. In the dense city centres, this flux is limited by a strong aerodynamic resistance (high $z_{o m} / z_{o t}$ roughness length ratio), favouring heat storage;
- A large heat storage in building materials, rather than in the ground, as a function of building density and morphology;

- A low but highly variable latent heat flux;

- A hysteresis in the diurnal cycles, with phase lags between the energy budget components due to heat being diverted from the budget and provisionally stored in the building materials in the morning at the expenses of the sensible heat, while the stored heat is released in the evening and at night.

Therefore, to improve meteorological forecasts for urban areas and to provide the high resolution meteorological fields needed by urban air quality (UAQ) models, it is required to implement specific urban surface layer and SEB parameterizations into meso-meteorological and NWP models, or so to speak to "urbanise" these models. It is necessary to stress that the requirements in model urbanisation for NWP and for UAQ applications are different, e.g., for NWP purposes it is the most important to produce correctly the urban surface fluxes on the first model level, however for UAQ modelling the vertical structure of UBL and urban canopy sublayer is also very important.

The improvement of UBL formulations and parameterisations using urban physiographic data classifications in NWP models together with the evaluation of the induced simulation improvements for urban meteorology for NWP and UAQ forecasting was one of the main aims of the EU-funded FUMAPEX project (Integrated Systems for Forecasting Urban Meteorology, Air Pollution and Population Exposure; Baklanov et al., 2006a).

The following meso-meteorological and NWP models of FUMAPEX partners were used for urban conditions or for different variants of the "urbanisation" scheme (user/developer teams are in brackets, cf. Appendix): 1. DMI-HIRLAM (DMI); 2. Local Model LM (DWD, MeteoSwiss, EPA Emilia-Romagna); 3. MM5 (CORIA, met.no, UH); 4. RAMS (CEAM, Arianet); 5. Topographic VorticityMode TVM Mesoscale Model (UCL); 6. Finite Volume Model FVM (EPFL); 7. SUBMESO (ECN).

This paper reviews works and advances achieved within FUMAPEX with respect to: (i) Finer spatial grid resolution and model downscaling; (ii) Detailed physiographic data and land-use classification; (iii) Calculation of effective urban roughness; (iv) Estimation of urban heat fluxes; (v) Urban canopy and soil sub-models.

\section{Specific challenges and approaches for the represen- tation of urban surface conditions, fluxes and energy balance}

As noted above, the urban atmospheric layer with its specific features implies a reconsideration of the ways the surface en- 
ergy balance (SEB), turbulent fluxes and the urban sublayer features are described and parametrised.

\subsection{Urban land-use classification and algorithms for rough- ness parameters}

Surface characteristics such as albedo, thermal properties, roughness, or moisture availability significantly control the SEB partitioning of any type of surface. In contrast to most natural surfaces, urban landscapes show a much wider range and larger variability of surface characteristics. However, most of the NWP and meso-meteorological models still do not consider any urban class at all, or include only one urban class for all types of urban surfaces. In view of the wide range of urban surface types, it is not possible to single out one set of universal urban surface values, which would be valid for all types of urban neighbourhoods worldwide. Therefore, much more detailed surface information than in existing NWP models is needed.

Typical surface characteristics can be attributed to distinct categories of urban land use classification (LUC). Such a classification can be performed based on land use maps or aerial photos. Digital LUC datasets can help to define different urban classes and are a source of increasing importance. Unfortunately, most LUCs are classified by functional aspects (residential, industrial) and not by surface morphometry or surface cover. Focussing on meteorological aspects, Ellefsen (1991) classified North American cities into 17 Urban Terrain Zones (UTZ) according to building contiguity, construction, and materials, defined by a written description and an array of model photographs. Fehrenbach et al. (2001) have automated the classification of urban climatological neighbourhoods from satellite image analysis. However, no universal classification scheme exists. Historical and socio-economical developments have led to a broad variety of urban neighbourhood types worldwide. The more complete the description scheme is, the more it is restricted to a specific (historical) region, e.g., Ellefsen's UTZs are difficult to apply to European cities because typical morphometry and building materials are different.

An appropriately chosen set of surface parameters can be related to specific physical processes. For example, it is not surprising that the area covered by vegetation drives the magnitude of the latent heat flux, or that morphometric parameters help to describe the roughness and turbulence characteristics over a particular urban surface. Therefore, the following three most important characteristics can be outlined (cf. Piringer and Joffre, 2005, for a summary).

(i) The Urban cover: 2-D plan aspect ratios ("plan area fractions") describe the 2-D surface fraction of a particular surface type per total plan area (as viewed from above), e.g. the plan area ratios of buildings, vegetation, impervious, and covered surfaces. It can also include dominant street directions in a grid cell. (ii) The Three dimensional structure: 3-D morphometric parameters describe the configuration of urban buildings (it can include vegetation as well). They are used in the BEP model to parameterize drag and turbulence production (see Sect. 4.3) or in the SM2-U model to simulate storage heat flux densities and surface temperatures (see Sect. 4.4).

The most important morphometric parameters to be used in urban meteorology models include: the mean building height, frontal aspect ratio, surface enlargement, normalized building volume, characteristic inter-element spacing, canyon width, building breadth, etc. For many cities, authorities provide digital 3-D building data sets, which are a powerful tool for the analysis of urban surface forms. Such high resolution data can provide detailed measures of 3-D parameters, and additionally vertical profiles, e.g., of building volume density and sky view factors.

(iii) Urban materials: This information (e.g., construction materials of buildings roofs and walls) is of great importance especially for the estimation of radiative properties (e.g. surface albedo) and the determination of storage heat flux densities. Detailed analysis of aerial photos or field surveys can provide the necessary information.

Proceeding from the urban LUC, the calculation of the main aerodynamic characteristics of urban areas such as the roughness length and displacement height, can be performed based on the morphometric or morphologic methods. Concerning morphometric methods, aerodynamic characteristics depend on the model intrinsic requirements for input data. Bottema and Mestayer (1998) and Grimmond and Oke (1999b) reviewed methods to deduce aerodynamic properties from a set of morphometric parameters. Tests of the models against individual datasets showed poor performances. The simplified model of Bottema (1997) gave relatively better results and additionally can be applied across the full range of building density parameters. It is an efficient alternative considering its relatively low input requirements.

More simple models cannot be recommended in particular due to their limited range of applicability. As to the "recommended rule of thumb" of Grimmond and Oke (1999b), one should keep in mind that it does not include any building density dependency of roughness and, therefore, will overestimate roughness for low and high densities, and underestimate it at medium densities.

With morphologic methods, a more empirical and pragmatic approach can be considered based on the visual observation of the physical structure of the urban canopy (e.g., from aerial photography). From survey of experimental data, Grimmond and Oke (1999b) offered a first-order evaluation of the roughness parameters of urban zones, separated into only 4 categories. These categories are associated with 4 flow regimes: (1) Low height and density - isolated flow; (2) Medium height and density - wake interference flow; (3) Tall and high density - skimming flow; (4) High rise - chaotic or mixed flow. 

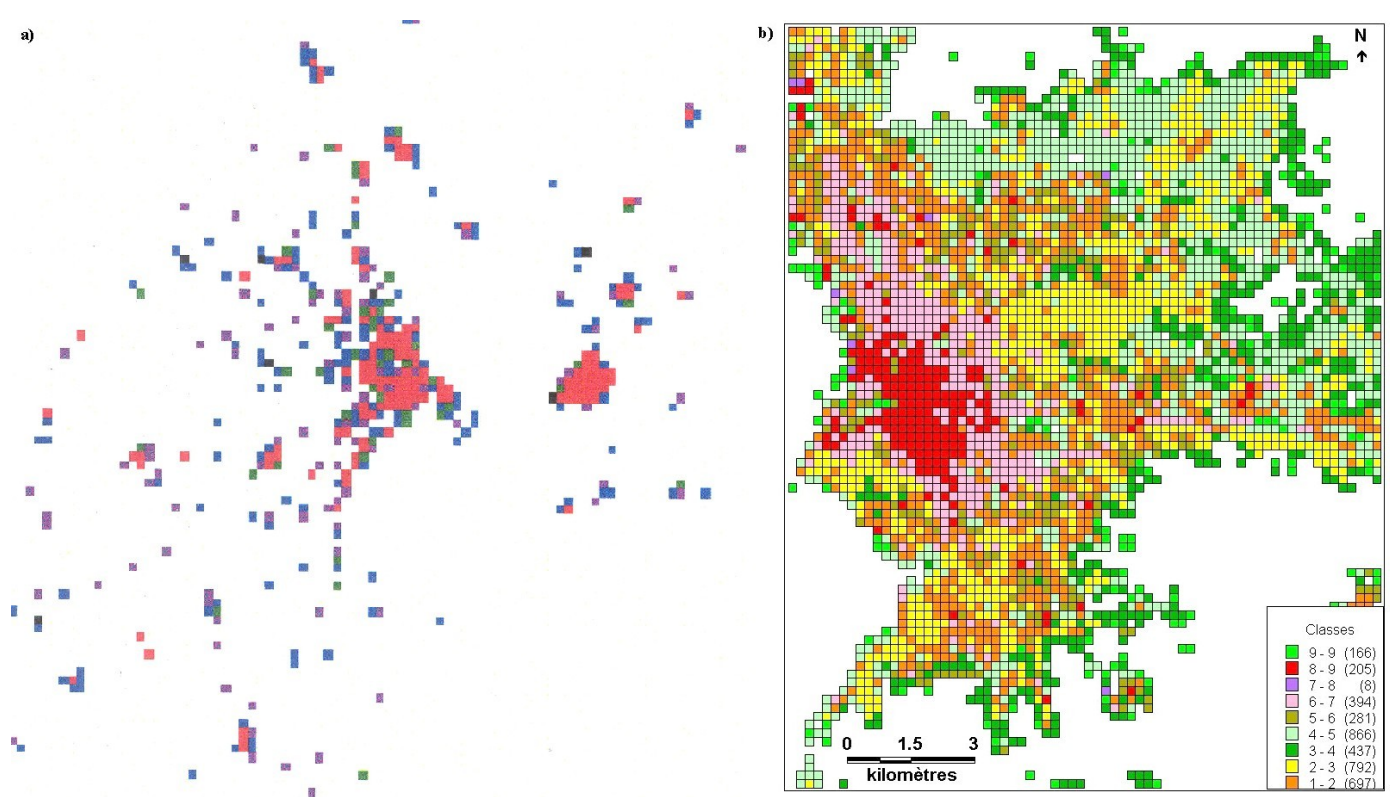

Fig. 1. Examples of improved urban land-use classifications prepared for: (a) the Copenhagen metropolitan area (shown as a percentage of the urban class representation in each grid-cell of the domain) used in the DMI-HIRLAM simulations; (b) the Marseilles metropolitan area (shown as a presence of 9 classes in domain, see Long, 2003) used in simulations of the SUBMESO model urbanized with SM2-U module.

Grimmond and Oke (1999b) adapted the Ellefsen (1991) scheme with 17 UTZ types to their proposed 4 urban roughness categories, offering physical description, matrix of typical photographs, and table of the most probable nondimensional roughness parameters. Also, the classical Davenport classification of effective terrain roughness was revised for the above mentioned categories by explicitly including the urban terrains (Davenport et al., 2000; Mestayer and Bottema, 2002).

Depending on the choice of the urbanisation approach (see Sect. 3) different urban LUCs are possible. In FUMAPEX, from 3 to 9 urban types were considered for different cities. Figure 1 presents two examples of the urban land-use classification, prepared following the above mentioned improved morphologic method, for the Copenhagen and Marseilles urban areas. The urban topographic databases BDTopo (French National Geographic Institute) for Marseilles and the AIS Land-use database (Danish Environmental Research Institute) for Copenhagen were used to analyse urban structures in order to characterise the morphology of settlements and land coverage (Long et al., 2002; Mahura et al., 2005). The accuracy of the computed descriptive statistics was estimated for different sizes of grid cells. It was found that individual cells of $200 \times 200 \mathrm{~m}$ represent best the structure of each urban district with respect to both high resolution and statistical representativeness (Long, 2003; Long and Kergomard, 2005). Therefore, mean variables describing the buildings morphology and land covers were computed for this size cells onto a grid and composed as layer themes in geographical information systems (GIS): building average height, perimeter, volume, compactness, plan area, vegetation and pavement densities, etc.

\subsection{Effect of the urban canopy roughness}

Theoretically, the Monin-Obukhov similarity theory (MOST) should not be applied below the blending height, the level above which surface inhomogeneities are not perceived anymore, i.e., where the various induced internal layers merge into a quasi-homogeneous horizontal structure. Thus, even using a modified urban roughness cannot provide a satisfying solution for the urbanisation of NWP model. As a compromise solution, to avoid or minimise the issue of protuberant roughness elements, it is suggested to consider the MOST profiles in NWP models only above an elevated level of the order of three times the displacement height $z_{d}$ since in most of the urban districts the rule of thumb $z_{d} \approx 2 / 3 h_{b}$ ( $h_{b}$ is the mean building height) applies quite well and there is consensus that the blending height $z_{b} \approx 2 h_{b}$. Therefore, in the suggested algorithm, the roughness for urban areas is characterised by, at least, two parameters: the roughness length and displacement height. Theoretical aspects of such an approach were discussed by Rotach (1994, 1998), Belcher and Coceal (2002), Belcher et al. (2003), Zilitinkevich et al. (2006b) and the COST-715 Action (Fisher et al., 2005).

Roughness parameters for urban areas are calculated by a modified algorithm based on the morphological methods (see Sect. 2.1). The displacement height is calculated only for grid-cells tagged as urban class following Fisher et al. (2005). 
The roughness length is calculated for each grid-cell in the following way: (i) constant values in each urban sub-class are tabulated for the urban class; (ii) the effective roughness is calculated based on values and percentages of each landuse class and urban sub-classes in the cell; (iii) at each time step, the roughness value is recalculated for the effect of temperature stratification.

In the general case of very inhomogeneous surfaces, such as urban areas, in order to include mutual effects of neighbouring cells, it would be reasonable to simulate the effective roughness fields for grid-cells of a given city separately for different situations (e.g., for different seasons, wind directions) and to build a kind of effective roughness map library. In such a strategy, the flux aggregation technique of Hasager et al. (2003) was tested in the DMI-HIRLAM model but at the current stage only for non-urban areas, because there is not enough experimental data to verify urban areas parameterisations and to check the technique linear approximation applicability to urban conditions.

Nevertheless, most of NWP and meso-meteorological models consider the roughness length as a constant for each grid cell. Experimental data (Arya, 1975; Joffre, 1982; Wood and Mason, 1991) showed that it can depend on temperature stratification. This effect can be considerable especially for very rough surfaces, like the urban canopy. Therefore, Zilitinkevich et al. (2006b) have derived an algorithm for recalculating the effective roughness as depending on a stabilitydependent parameterisation of the urban roughness length for momentum. The formulation for the effective roughness length for neutral and stable stratification regimes reads:

$z_{0 \mathrm{~m}-\text { effective }}=\frac{z_{0 m}}{1+C_{0 S} z_{0 m} / L+C_{0 \nu} z_{0 m} u_{*} / \nu}$,

where $C_{0 v} \approx 10, C_{0 S}=10 C_{u} \kappa^{-1} \approx 50$ are empirical constants, while for unstable stratification:

$\frac{z_{0 m-\text { effective }}}{z_{0 m}}=\left[C_{0}-\left(C_{0}-1\right) \exp \left(-C_{1} z_{0 m} /|L|\right)\right]$,

where $C_{0}$ and $C_{1}$ are empirical constants. The theoretical background for these formulations, their verification versus experimental data and choice of the constants are discussed in details by Zilitinkevich et al. (2006a, b).

However, just modifying the current rural MOST approaches for urban areas with specific values for the effective roughness lengths and displacement height, still does not solve the main problem, i.e., how to describe the vertical structure of meteorological variables inside the urban canopy? We can suggest here to apply the new simple heuristic model of Zilitinkevich and Baklanov (2005) for the vertical profiles of the momentum flux and the mean wind velocity within the urban canopy. It considers the vertical wind profile inside the canopy (below the displacement height) as an analytical function of the average building height, size and density, as well as of some meteorological parameters.

It is noteworthy that the suggested improvements based on the canopy profile model and displacement height do not require to substantially modify the NWP model itself, because the first computational model level is usually above the canopy, so that the canopy parameterisation can be used only for diagnostic calculation of the wind in higher resolution UAQ models outside of the NWP model or for diagnosing the $10 \mathrm{~m}$ wind in NWP.

\subsection{Surface energy budget in urban areas}

In general, the SEB in urban areas can be written in the following way (Piringer and Joffre, 2005):

$Q *=K \downarrow-K \uparrow+L \downarrow-L \uparrow=H+L E+Q_{A s}\left[\mathrm{~W} / \mathrm{m}^{2}\right](3)$ where $Q *-$ net all-wave radiation; $K \downarrow$ - incoming shortwave radiation; $K \uparrow=\alpha_{0} K \downarrow$ - outgoing, reflected shortwave radiation where $\alpha_{0}$ - surface albedo; $L \downarrow$ - incoming longwave radiation from the sky and surrounding environment "seen" from the point; $L \uparrow=\varepsilon_{0} \sigma T_{0}^{4}+\left(1-\varepsilon_{0}\right), L \downarrow$ - outgoing longwave including both that emitted from the surface consistent with its emissivity $\varepsilon_{0}(\sigma)$ is the StefanBoltzmann constant) and absolute surface temperature $T_{0}$, and the reflected incoming longwave; $H$ - turbulent sensible heat flux; $L E$ - turbulent latent heat flux ( $L$ is the latent heat of vaporisation); $Q_{A s}$ - specific urban anthropogenic surface heat flux. Thus, the urban formulation differs from the non-urban one only by the $Q_{A s}$ term.

This formulation is suitable for detailed urban canopy models (see e.g. Sects. 4.3 and 4.4), when the surface is just millimetres above ground and the canopy layers are within the simulation domain. For meso-scale meteorological and NWP models in which the surface may be high above the urban canopy (average roughness level or displacement height), the SEB can be rewritten in the following form:

$Q *=K \downarrow-K \uparrow+L \downarrow-L \uparrow=H+L E+Q_{A}+\Delta Q_{S}$ $\left[\mathrm{W} / \mathrm{m}^{2}\right]$

where $Q_{A}$ is the anthropogenic heat flux from sources within the urban canopy and $\Delta Q_{S}$ is an imbalance term, which includes the storage heat flux in the urban canopy elements, the ground and the air layer, extending from the surface to a level where the vertical heat exchange divergence is negligible (i.e., the constant flux layer).

Correspondingly, in such a model most of the terms of Eq. (4) are simulated for urban grid cells as usual with corresponding urban characteristics, but we need to define and parameterise two new urban terms: $Q_{A}$ and $\Delta Q_{S}$ as well as the albedo for urban areas.

\subsubsection{Urban anthropogenic heat flux calculation}

Estimations of the average anthropogenic heat fluxes (AHFs) for cities in different climatic zones (Oke, 1978) yield reference values in the range from 60 to $200 \mathrm{~W} / \mathrm{m}^{2}$, depending on the city size, for a full urban area $(100 \%$ of urban class; e.g., city centre or high building district). Information on the 
spatial distribution of AHFs over a city is not available from monitoring data and is difficult to obtain from measurements (e.g., Pigeon et al., 2005, showed for Toulouse that $Q_{A}$ estimates are very uncertain and consequently can display negative values during summer months). Therefore, we suggest calculating the urban AHF based on an assumed dependency on (e.g., proportionality to) other relevant urban characteristics, which are available in the models, e.g.:

1. Population density using maps with a high resolution in urban areas;

2. Nocturnal radiation emissions (brightness) over urban areas based on high resolution satellite images;

3. Land-use classification as a percentage of urban subclasses (central part, urban, sub-urban, industrial, etc.);

4. Emission inventory for specific pollutants typical of urban areas (e.g., $\mathrm{NO}_{\mathrm{x}}$ from traffic emissions, $\mathrm{CO}_{2}$ from combustion activities, etc.);

5. Monitoring or simulation fields of air pollution concentration for such specific pollutants (see above \#4).

The first method with AHF as a function of the population density distribution in urban areas is the one most frequently used and was tested for FUMAPEX NWP models. For the second method based on the nocturnal brightness of urban areas, it is suggested to use the simple dependence: $Q_{A}=I_{l n} Q_{\text {Amax }}$, where $I_{l n}$ is the normalised light intensity (max value is 1 ), and $Q_{\text {Amax }}$ is a scale (max) value of the AHFs for $100 \%$ of urban surface (from $50 \mathrm{~W} / \mathrm{m}^{2}$ for small/medium cities and up to $200 \mathrm{~W} / \mathrm{m}^{2}$ for large megacities in industrially developed countries). However, it is important to notice that the brightness of urban areas is different for industrial vs. developing countries, and hence the method should be corrected accordingly.

The third method using land-use classification as a percentage of urban classes was tested for the Copenhagen and Krakow study in COST-715 (see Piringer and Joffre, 2005). The anthropogenic part to the urban surface fluxes was approximated according to a coarse urban LUC: (i) $75 \mathrm{~W} / \mathrm{m}^{2}$ for the city centre, (ii) $40 \mathrm{~W} / \mathrm{m}^{2}$ for city periphery areas, and (iii) $20 \mathrm{~W} / \mathrm{m}^{2}$ for other urban-suburban areas.

The last two methods (Eqs. 4 and 5), based on urban emissions or air pollution, can be easily used in atmospheric pollution forecasting models, because such information is usually available in the simulation.

\subsubsection{Urban storage heat fluxes}

Storage heat fluxes in the urban canopy are considered in our system by two different approaches. First, the heat storage capacity effect can be calculated using specific parameterisations for the temperature and moisture roughness lengths of urban areas. Most of NWP and meso-meteorological models consider for their surface layer profiles that the scalar roughness length, $z_{0 t}$, is equal to the roughness for momentum, $z_{0 m}$. However, for urban areas, they are generally very different (up to 2-3 orders of magnitude). Theoretical studies (Zilitinkevich, 1970; Brutsaert, 1975) suggest that the ratio $z_{0 t} / z_{0 m}$ is a function of the roughness Reynolds number $R e_{*}=z_{0 m} u_{*} / v$ ( $u_{*}$ is the friction velocity and $v$ the kinematic molecular viscosity of air). Thus, the formulation of Brutsaert and Sugita (1996) for example can be suggested for urban areas. Including the modification by Joffre (1988), using the Reichardt's profile, to the Brutsaert's assumption concerning the level below which the log-profile is not valid, the following formulation can be recommended for various bluff types of roughness over a wide range of the roughness Reynolds number $\left(0.1 \leq R e_{*} \leq 100\right)$ :

$z_{0 t}=z_{0 m}\left[20 \exp \left(-7.3 \kappa a_{c} R e_{*}^{0.25} S c^{1 / 2}\right)\right]$,

for $R e_{*}>0.15$

where $a_{c}$ is the inverse turbulent Schmidt number $\left(=K_{H} / K_{M}\right.$ for $z_{0 t}$ or $K_{E} / K_{M}$ for $\left.z_{0 q}\right) k$ the von Karman constant $(k=0.4)$ and $S c$ the Schmidt number $\left(=v / D_{c}, D_{c}\right.$ is the molecular diffusivity of the particular property, i.e., heat, moisture but also gaseous compounds). The original Brutsaert's formula had a coefficient 7.4 instead of 20 in the first term of the righthand side and was valid for $R e_{*}>2$ (rough case only). Equation (5) matches the corresponding expression (6) valid for aerodynamically smooth case at $R e_{*}=0.15$, i.e.:

$z_{0 t}=30(v / u *) \exp \left[-13.6 \kappa a_{c} S c^{2 / 3}\right]$ for $R e_{*}<0.15$

However, this and other existing formulations are very uncertain, rarely verified and cannot consider all the mechanisms of the urban heat storage.

Therefore, the heat storage in the urban fabrics/buildings, including hysteresis, can be most easily parameterised from the radiation and surface cover information using the empirical objective hysteresis model (OHM) of Grimmond et al. (1991):

$\Delta Q_{S}=\sum_{i=1}^{n}\left(\lambda_{i} \alpha_{1 i}\right) Q *+\sum_{i=1}^{n}\left(\lambda_{i} \alpha_{2 i}\right) \partial Q * / \partial t+\sum_{i=1}^{n}\left(\lambda_{i} \alpha_{3 i}\right)$ $\left[\mathrm{W} / \mathrm{m}^{2}\right]$

where the $\lambda_{i}$ are the plan fractions of each of the $n$ surface types in the area of interest and the $\alpha_{1-3 i}$ are the corresponding empirical coefficients. These $\alpha$ coefficients have been deduced from a re-analysis of the Multi-city Urban Hydrometeorological Database obtained from ten sites in seven North American cities (Grimmond and Oke, 1999a).

\subsubsection{Urban albedo effects}

Radiative properties (such as albedo and emissivity) of building and ground-covering materials are very different from those of natural grounds and vegetation, while the vertical 
structure of spaces between buildings provides shade and radiation trapping. In addition, they have not only horizontal but also vertical and/or slanted orientations, which strongly alter the radiative transfers and energy budget. The heat flux to or from the ground changes with surface material: concrete, tarmac, soil, etc. Anthropogenic energy use can be a noticeable fraction of the annual solar input and thus, influences the local air stability.

\section{FUMAPEX methodology for urbanization of city- scale meteorological models}

The FUMAPEX strategy to improve NWP and meso-scale meteorological models includes the following steps for the urbanisation of relevant submodels or processes:

1. Model down-scaling by increasing vertical and horizontal resolution and nesting techniques (one- and two-way nesting), see section 4.1;

2. Specific parameterization of the urban surface fluxes in meso-scale models (see Sect. 4.2);

3. Modified high-resolution urban land-use classifications, together with updated parameterizations and algorithms for roughness parameters in urban areas based on the morphometric method (see Sects. 2.1 and 4.2);

4. Modelling/parameterization of meteorological fields within the urban sublayer (Sects. 4.3 and 4.4);

5. Calculation of the urban mixing height based on prognostic approaches.

These steps are not all exclusive of each other and some of their couplings are shown in Fig. 2 together with the general hierarchy of models and pre-prosessors.

As to simulating urban canopy effects in urban-scale NWP and meso-meteorological models, it can be considered with the following two approaches:

1. Modifying the existing non-urban approaches (e.g., the MOST) for urban areas by finding proper values for the effective roughness lengths, displacement height, and heat fluxes (adding the anthropogenic heat flux $\left(Q_{A}\right)$, heat storage capacity and albedo change). In this case, the lowest model level is close to the top of the urban canopy (displacement height), and a new analytical model is suggested for the urban roughness sublayer which is the critical region where pollutants are emitted and where people live (Zilitinkevich and Baklanov, 2005).

2. Alternatively, source and sink terms can be added in the momentum, energy and turbulent kinetic energy equation to represent the effects of buildings. Different parameterizations (Masson, 2000; Kusaka et al., 2001;

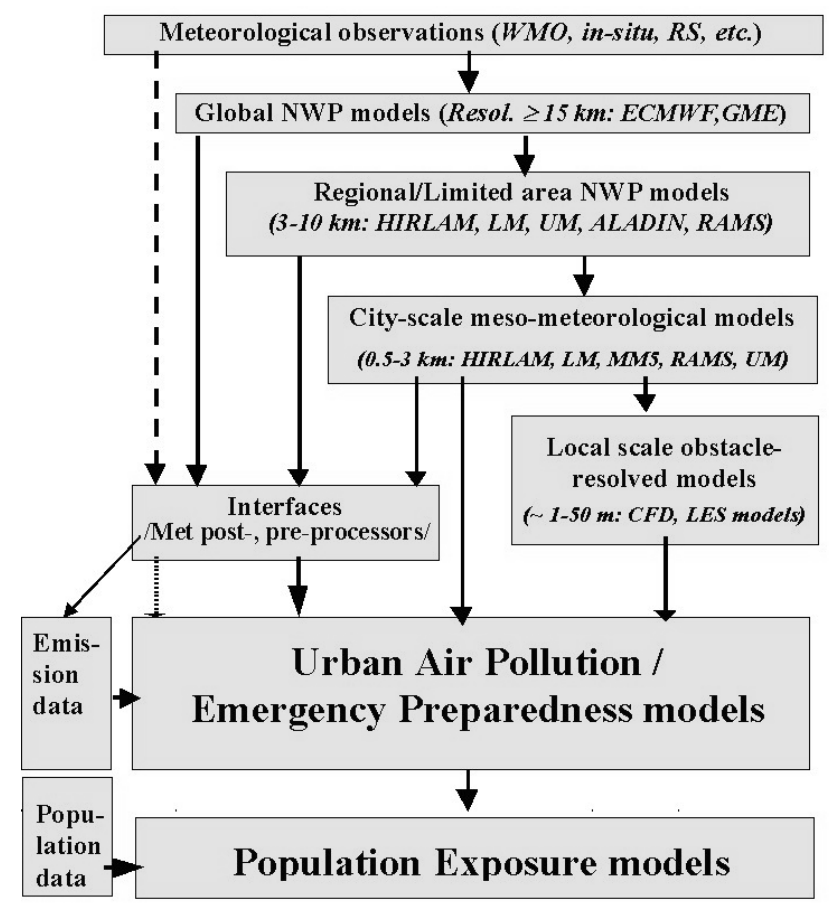

Fig. 2. Current regulatory (dash line) and suggested (solid line) ways for forecasting systems of urban meteorology within UAQIFSs by downscaling from the adequate NWP models to the urban scale (adapted from Baklanov et al., 2002).

Martilli et al., 2002) have been developed to estimate the radiation balance (shading and trapping effect of the buildings) as well as the heat, momentum and turbulent energy fluxes inside the urban canopy, and considering a simple geometry of buildings and streets (3 types of surfaces: roof, wall and road).

In a first stage, three modules for NWP model urbanisation were developed for further testing and implementated into NWP models or their postprocessors. These FUMAPEX modules are:

1. The DMI module: Based on the first approach, it includes a new diagnostic analytical parameterisation of the wind profile into the urban canopy layer (Zilitinkevich and Baklanov, 2005), a higher resolution and improved land-use classification. Existing physical parameterisations of the surface layer in NWP models are corrected as to the surface roughness for urban areas (with the incorporation of the displacement height) and to heat fluxes (addition of the AHF via heat/energy production/use in the city, heat storage capacity and albedo change). It is realised in the city-scale version of the DMI-HIRLAM model.

2. The Building Effect Parameterisation (BEP) module of the EPFL: Based on the second approach and the urban surface exchange parameterisation submodel (Mar- 


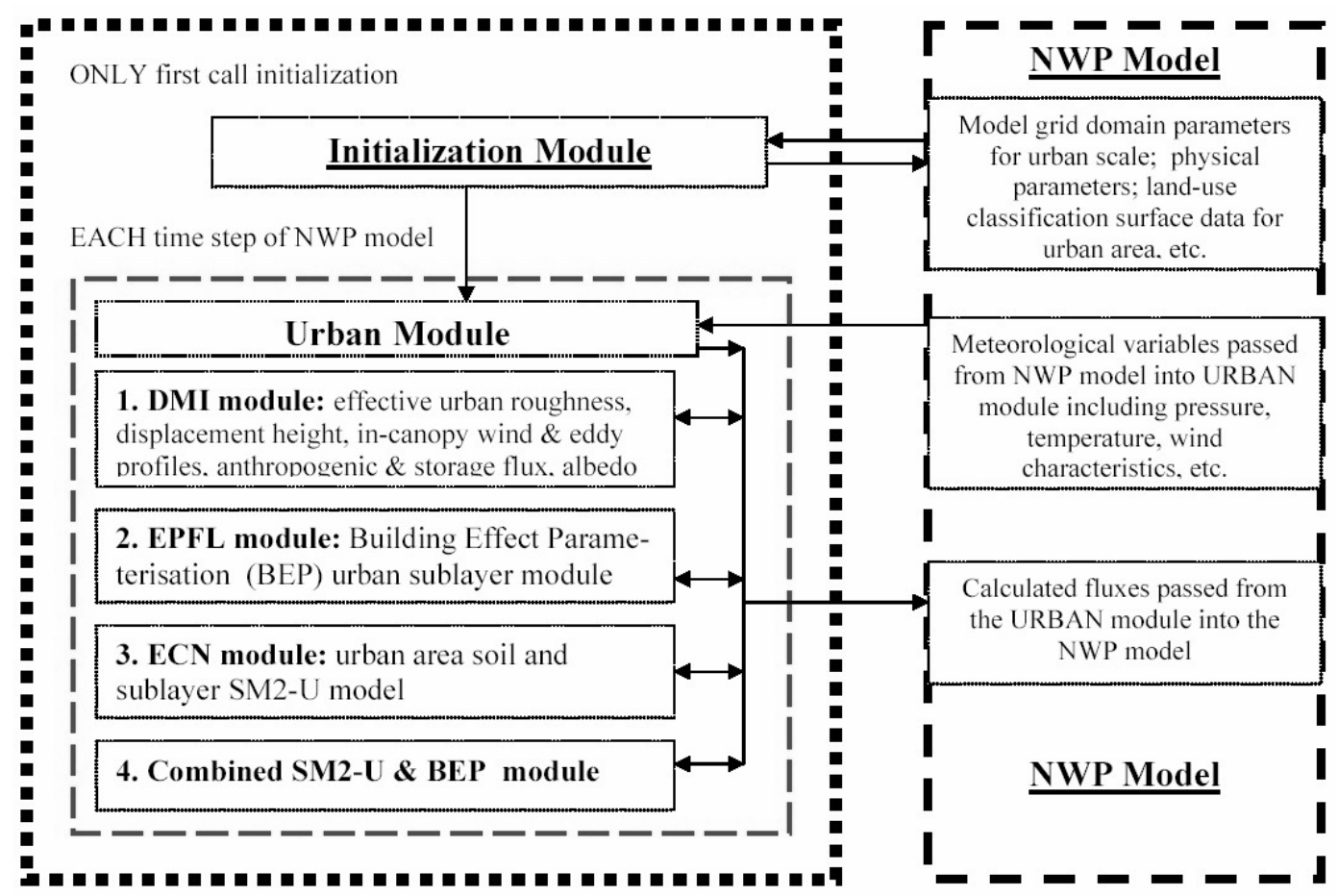

Fig. 3. General scheme of the FUMAPEX urban module for urbanisation of the numerical weather prediction models.

tilli et al., 2002). It was first tested with the research meso-meteorological FVM and TVM models and now is considered for incorporation into the DMI-HIRLAM and LM NWP models.

3. The ECN module: Based on the detailed urban area soil and sublayer SM2-U model (Dupont, 2001; Dupont et al., 2005). It was first tested with the large eddy simulation SUBMESO research model, then implemented in MM5 (Otte et al., 2004), and is also considered for the DMI-HIRLAM NWP model.

Additionally to the above mentioned approaches, the flux aggregation technique of Hasager et al. (2003) was installed in the DMI-HIRLAM model for non-homogeneous surfaces. However, it has not yet been tested for urban areas. The main idea of our urban module architecture was to build it as much as possible independently of the type of NWP models, and to allow a simple implementation into different models. Note that it is not possible to build it as a completely independent module, but the urban modules were modified substantially to satisfy the main requirements and formats of NWP models. There is also freedom on how to implement the module: either to incorporate it inside the NWP model code or to call the separate module from the NWP code. The flow chart to call the module by the NWP model is presented in Fig. 3. The initialisation module is called only once when the model is initialised for simulations, and then the urban module (1, 2,3 or 4 ) - at every time step during the simulation.
The urban canopy modules can be built as an interface/post-processor module separated from the NWP model. In such case, the urban sublayer model will be run separately (using previously simulated NWP data as a fist approximation) and will improve the meteorological fields in an area close to and inside the urban canopy with higher resolution (cf. one example in Sect. 4). Obviously, such a strategy is less promising, because it does not yield any improvement of the meteorological forecast in urban areas and cannot allow feedbacks. For UAQ modelling/forecasting, this approach can, however, be very useful and easier to implement, because it does not require any modification of the operational NWP model (which is usually complex and timedemanding). Thus, in such a novel approach, one can consider the urban sublayer modules (including several upper layers and surrounded areas) as interface modules between the NWP and UAQ models.

\section{Modelling results on the "urbanisation" of surface characteristics and fluxes}

\subsection{Increased grid resolution and nesting of NWP models}

Increased computer power and the implementation of grid nesting techniques allows modern NWP models to approach the resolution necessary for the city-scale. The FUMAPEX strategy for improving UAQIFS includes, first of all, increas- 
ing model resolution and down-scaling (with one- or twoway nesting) of NWP models with different resolutions.

For example, the recent Danish operational NWP system (Sass et al., 2002) consists of several nested models named DMI-HIRLAM-S05 and -T15, with horizontal resolutions of 5 and $15 \mathrm{~km}$, respectively. The previous nested versions G45, E15 and D05 (operational prior to 14 June 2004) had 45, 15 and $5 \mathrm{~km}$ resolutions, correspondingly. The vertical resolution of the operational versions is 40 levels, but it was increased up to 60 levels for test runs. In FUMAPEX, DMI ran also several experimental versions of DMI-HIRLAM (e.g., U01, I01) with a horizontal resolution of $1.4 \mathrm{~km}$ over Denmark and the Sjælland Island, where the city of Copenhagen is located (Baklanov et al., 2002; Fay et al., 2005; Mahura et al., 2006).

The German DWD Local Model LM (Doms and Schättler, 1999) is currently operated as a nest within the Global Model for Europe. LM has a resolution of $7 \mathrm{~km}$ for the Central and Western Europe. In 2003, it became operational for that area with a resolution of $2.8 \mathrm{~km}$. For the FUMAPEX study, both the horizontal and vertical resolution of LM were increased to $1.1 \mathrm{~km}$ and 43 layers, respectively, as required by the 1 way self-nesting version of LM (Fay and Neunhaeuserer, 2006).

In Norway, the non-hydrostatic MM5 model (Grell et al., 1994) is nested with the HIRLAM NWP model (Berge et al., 2002). The latter model is operated on a $10 \mathrm{~km}$ horizontal resolution for North-Western Europe. A domain with a resolution of $3 \mathrm{~km}$ has been set up for the region around the city of Oslo in which MM5 is one-way nested with HIRLAM. A two-way nesting takes place between the $3 \mathrm{~km}$ resolution domain and a $1 \mathrm{~km}$ resolution area covering Oslo. The MM5 output is input to the Air Quality Model of the Norwegian Institute for Air Research.

FUMAPEX partners performed verification and sensitivity studies with their high-resolution NWP models versus measurement data for several episodes in different European cities: Helsinki, Oslo, Bologna, Valencia, Copenhagen (Neunhaeuserer et al., 2004; Fay et al., 2005; Baklanov, 2005). Results for the verification of the LM model using different resolutions are discussed by Fay and Neunhaeuserer (2006) and for the Norwegian urban nested MM5-HIRLAM system by Berge et al. (2002). Verifications for high-resolution versions of the DMI-HIRLAM modelling system were carried out for Copenhagen by Baklanov et al. (2006c) and Mahura et al. (2006).

Figure 4 presents one example of sensitivity test results for the DMI-HIRLAM-U01 research model with a $1.4 \mathrm{~km}$ resolution for May 2005. It shows better prediction of the diurnal cycle of the average wind velocity at $10 \mathrm{~m}$ than with the $\mathrm{S} 05$-version. The verification runs underlined that increasing the resolution (down to $1 \mathrm{~km}$ ) improves the performance of the meteorological forecast. Nevertheless, it will be also very important for further improvements to have more de-

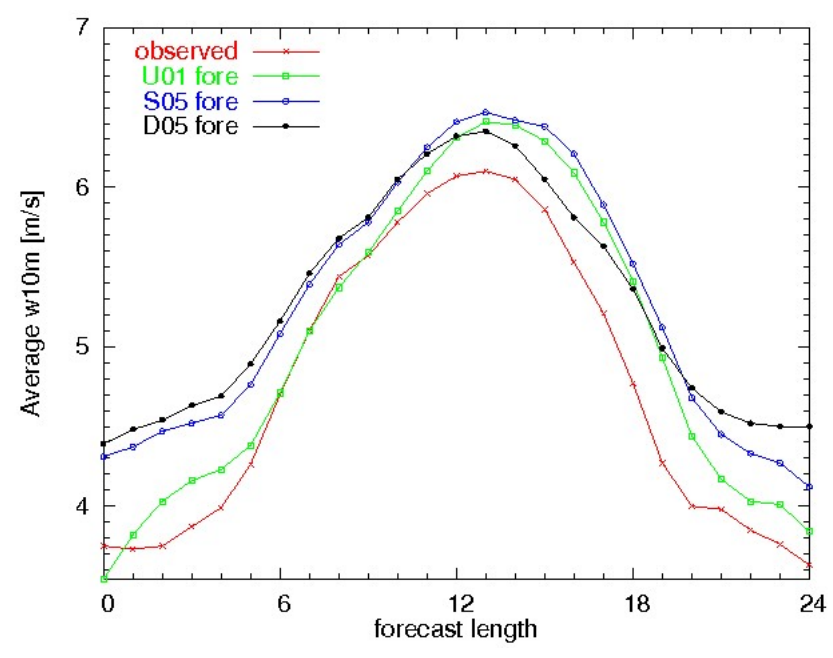

Fig. 4. Diurnal variation of average wind velocity (in $\mathrm{m} / \mathrm{s}$ ) at $10 \mathrm{~m}$ between observational data and three DMI-HIRLAM-S05, -U01, and -D05 models for 00:00 UTC forecasts during May 2005.

tailed surface feature databases and to increase the quality of the land-use classification (LUC) for urban areas.

4.2 Approach based on improved urban roughness and fluxes

The simplest urban module (DMI module in $\$ 3$ and Fig. 3) is based on the following requirements: (i) to be relatively cheap computationally and as close as possible to the parameterisations of the surface/boundary layer in the parent NWP models, (ii) to split the surface layer over urban areas into two/three sub-layers (see Fig. 4 in Fisher et al., 2006). This split distinguishes: (i) the roughness layer (including logarithmic layers), where the MOST can be used with correction to the urban roughness, and (ii) the urban canopy layer, where the MOST does not work and new analytical parameterisations for the wind and eddy profiles have to be considered.

The DMI-module includes algorithms for calculating the following urban parameters for the NWP model and steps for each model grid having urban features:

1. Land-use classification, including at least one urban class and several urban subclasses;

2. Displacement height for the urban (and forest) canopies;

3. Urban and effective roughness (and flux aggregation);

4. Stability-dependent urban roughness lengths for momentum;

5. Urban anthropogenic heat fluxes,

6. Urban storage heat fluxes by the Objective Hysteresis Model (OHM, Grimmond et al., 1991) or specific roughness lengths for heat and moisture; 

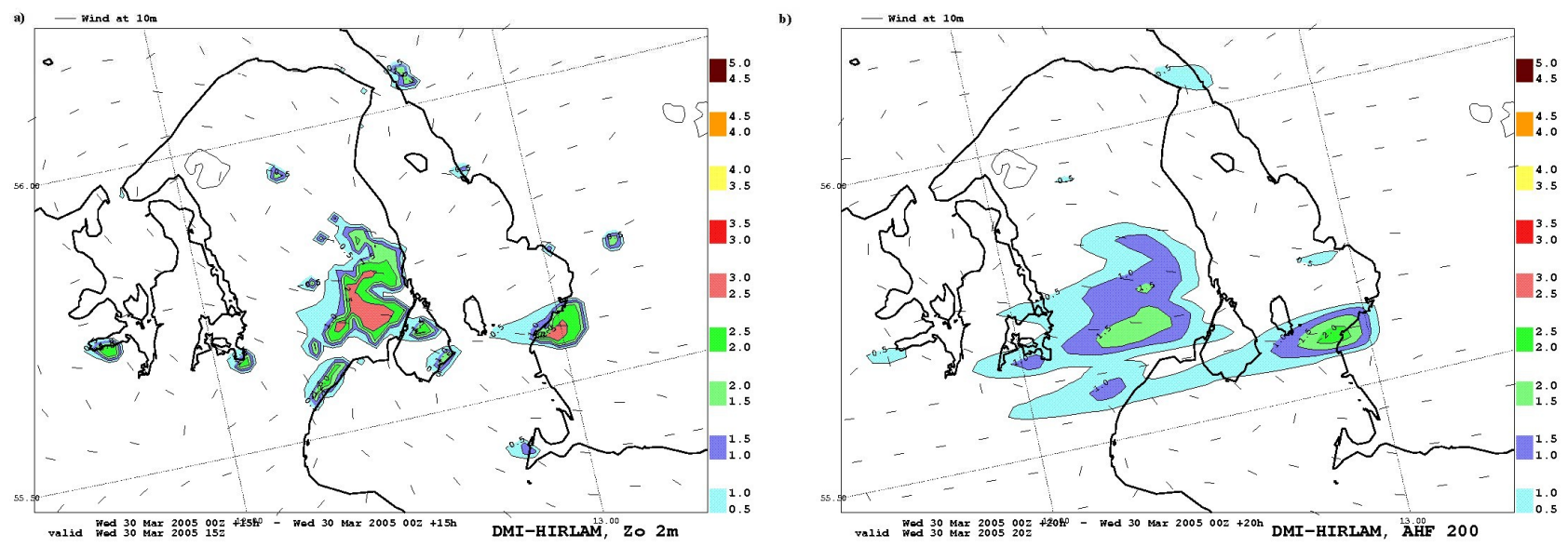

Fig. 5. Sensitivity tests to urban features with the DMI-HIRLAM high resolution model shown as the difference fields (runs without vs. with modifications) for the $10 \mathrm{~m}$ wind velocity separately with the inclusion of the (a) urban roughness and (b) anthropogenic heat flux over the Copenhagen and Malmö metropolitan areas on 30 March 2005.

\section{Albedo correction for urbanised surfaces;}

8. Prognostic mixing height parameterisations;

9. Parameterisation of wind and eddy profiles within the canopy layer.

It is reasonable to use this approach for relatively cheap simulations and for NWP models with a coarse vertical resolution (first computational vertical level is higher than $20 \mathrm{~m}$ ), when other more complex models of the urban sub-layer (e.g., BEP and SM2-U) would not much affect results or would be too expensive for operational forecasting applications.

Sensitivity tests and verification of this approach of NWP urbanisation were performed using the DMI-HIRLAM NWP research version $(1.4 \mathrm{~km}$ resolution) for the Copenhagen (CPH, Denmark) and Malmö (MAL, Sweden) metropolitan areas and surroundings. Independent runs were performed for several specific cases: (i) one control run with no modifications in the ISBA surface scheme (Noilhan and Planton, 1989); (ii) a modified urbanised version including urban roughness (up to $2 \mathrm{~m}$ when the urban class is $100 \%$ in a grid-cell) and anthropogenic heat fluxes (up to $200 \mathrm{~W} / \mathrm{m}^{2}$ ).

Simulation results showed that incorporating actual urban roughness values modified the structure of the surface layer wind field over urban areas (Fig. 5a). During daytime, the wind velocities were lower by $1-4 \mathrm{~m} / \mathrm{s}$. With a roughness $z_{0 \mathrm{~m}}$ of $2 \mathrm{~m}$, this effect became more visible and pronounced not only near CPH and MAL, but also for other less urbanised areas. At night, this effect was smaller. The average differences in velocities were 2.4 and $2 \mathrm{~m} / \mathrm{s}$ for $\mathrm{CPH}$ and MAL, respectively.

For temperature, the urban roughness effect did not contribute significantly compared to the wind effect. Incorporation of the anthropogenic heat flux showed (Fig. 5b) well pronounced differences (starting at 16:00 UTC) in the simulated wind fields over the $\mathrm{CPH}$ urban cells. Then, the altered area extended farther inland of the Sjælland Island, and the difference rapidly increased to $1.5 \mathrm{~m} / \mathrm{s}$ by 18:00 UTC. It also became well pronounced over MAL reaching the same value. For MAL, during the late evening - early morning hours the difference became the largest reaching a maximum of 2.1 $\mathrm{m} / \mathrm{s}$, and again by 10:00 UTC no difference was visible. For temperature, AHF increased the temperature above the urban cells, except that it was smaller during the 09:00-15:00 UTC period with a minimum at noon. For both urbanised areas, this increase was on average up to $1^{\circ} \mathrm{C}\left(\max 2.3^{\circ} \mathrm{C}\right)$ but with a large variance.

The analysis of the diurnal cycle at the urban Værløse station $\left(55.77^{\circ} \mathrm{N}, 12.33^{\circ} \mathrm{E}\right)$ located in central Copenhagen showed that the diurnal variability of the wind direction was modelled in all runs with practically no differences between the control and modified runs. A similar situation was observed for the suburban Jegersborg station $\left(55.77^{\circ} \mathrm{N}\right.$, $\left.12.53^{\circ} \mathrm{E}\right)$ and the Kastrup station $\left(55.62^{\circ} \mathrm{N}, 12.65^{\circ} \mathrm{E}\right)$ located not far from the seashore (so that urban effects were minimised during the studied day due to eastern winds).

Inspecting the wind velocity daily cycle at an urban station (Fig. 6, top) shows that between 07:00-19:00 UTC the run with the AHF reflects better the observed local maximum than the run with urban roughness, which alternatively better fits the observed local minimum. This means that the combined effect of both roughness and AHF should be included. It is noteworthy that for the suburban station, the modification including the improved roughness showed a better fit to observational data compared with all other runs. For temperature (Fig. 6, bottom), on the other hand, the fit to observations was now better for the urban compared to the suburban station (not shown) for the modified run with the AHF. Modifications of roughness did not improve the fit. More- 
over, in this specific example, we did not include the storage heat flux, therefore a time shift of the temperature field is observed in the diurnal cycle, especially during the transitional morning and evening periods. The objective hysteresis model (Grimmond et al., 1991) could improve this shortcoming.

It is important to remark that, in comparison with the original (non-urbanised) version of the model, the computational time is almost the same for this urbanised version. So, this variant of the urban parameterisations in NWP models is computationally very cheap.

4.3 Modifying NWP outputs for extra pressure and drag forces with the Building Effect Parameterization (BEP) module

The second module option of Fig. 4 was realised with the Building Effect Parameterization (BEP) model, developed by the Swiss partner EPFL. It is based on the urban sub-layer parameterisation suggested by Martilli et al. (2002) with modifications for implementation into NWP models and several further improvements (e.g., Hamdi and Shayes, 2006).

The aim of the urban BEP module (Martilli et al., 2002) is to simulate the effect of buildings on a meso-scale atmospheric flow. It takes into account the main characteristics of the urban environment: (i) vertical and horizontal surfaces (wall, canyon floor and roofs), (ii) shadowing and radiative trapping effects of the buildings, (iii) anthropogenic heat fluxes through the buildings wall and roof. In BEP the city is represented as a combination of several urban classes. Each class is characterised by an array of buildings of the same width located at the same distance from each other (canyon width), but with different heights (with a certain probability to have a given building height). To simplify the formulation, it is assumed that the length of street canyons is equal to the horizontal grid size. The vertical urban structure is defined on a numerical grid.

The contribution of each urban surface type (canyon floor, roofs and walls) on the momentum, heat and turbulent kinetic energy equations are computed separately. Firstly, the contributions of the horizontal surfaces (canyon floor and roofs) are calculated using the formulation of Louis (1979) based on the MOST. The roughness lengths used for this calculation are representative for the local roughness of the specific surface types (roofs or canyon floor) and not for the entire city, as it was considered in the DMI-module (Sect. 4.2).

Secondly, the exchange of momentum and turbulent kinetic energy on vertical surfaces (walls) is parameterised as the effect of pressure and drag forces induced by the buildings. The temperature fluxes from the walls are a function of the difference between the air temperature and the wall temperature. They are parameterised using the formulation of Clarke (1985) proposed by Arnfield and Grimmond (1998) in their urban energy budget model.

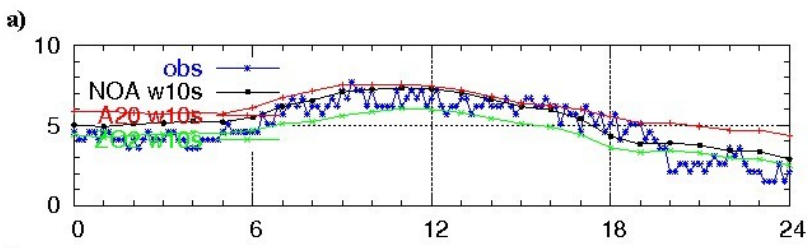

b)

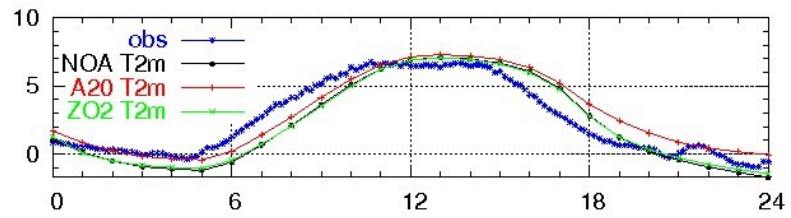

Fig. 6. Diurnal cycle (30 March 2005) of wind velocity at $10 \mathrm{~m}$ (w10s, in $\mathrm{m} / \mathrm{s}$; top panel) and air temperature at $2 \mathrm{~m}\left(\mathrm{~T} 2 \mathrm{~m}\right.$, in ${ }^{\circ} \mathrm{C}$; lower panel) based on the DMI-HIRLAM high resolution control run (NOA), modified runs with added anthropogenic heat flux (max $200 \mathrm{~W} / \mathrm{m}^{2}$ ) (A20) and urban roughness (max. $\left.2 \mathrm{~m}\right)(\mathrm{Z} 02) \mathrm{vs}$. observational data (obs) at Værløse urban station $\left(55.8^{\circ} \mathrm{N}, 12.3^{\circ} \mathrm{E}\right)$ located in central Copenhagen.

The energy budget is computed for every mentioned surface (canyon floor, roofs and walls). Initially, both shortwave and longwave radiative fluxes at the surfaces are calculated taking into account the shadowing and radiative trapping effects of the buildings. Then, the surface temperature of roofs, walls and canyon floor are solved with the heat diffusion equation over several layers within built materials (concrete or asphalt).

\subsubsection{Sensitivity to urban parameters}

The use of Martilli et al.'s (2002) parameterisation in a mesoscale model requires evaluating a number of input parameters. These parameters characterise the urban environment and they can be classified in three different groups. The first group consists of parameters characterising the building and street geometry (street width and direction, building width and height). The second group includes parameters characterising the building and street materials (heat capacity and diffusivity, albedo and emissivity, street and roof roughness length). The third group includes parameters characterising the energy produced inside the buildings (indoor temperature).

These various input parameters have diverse effects on the momentum and the energy fluxes, and thus influence the wind and temperature behaviour (Fig. 7). The wind velocity is mainly affected by the buildings walls drag force, which produces a negative momentum flux. Consequently, the higher are the buildings, the lower is the wind velocity inside the urban canopy (Fig. 7c).

On the other hand, temperature is influenced by two different energy sources: the anthropogenic sources (indoor temperature of building) and natural sources (direct solar radia- 

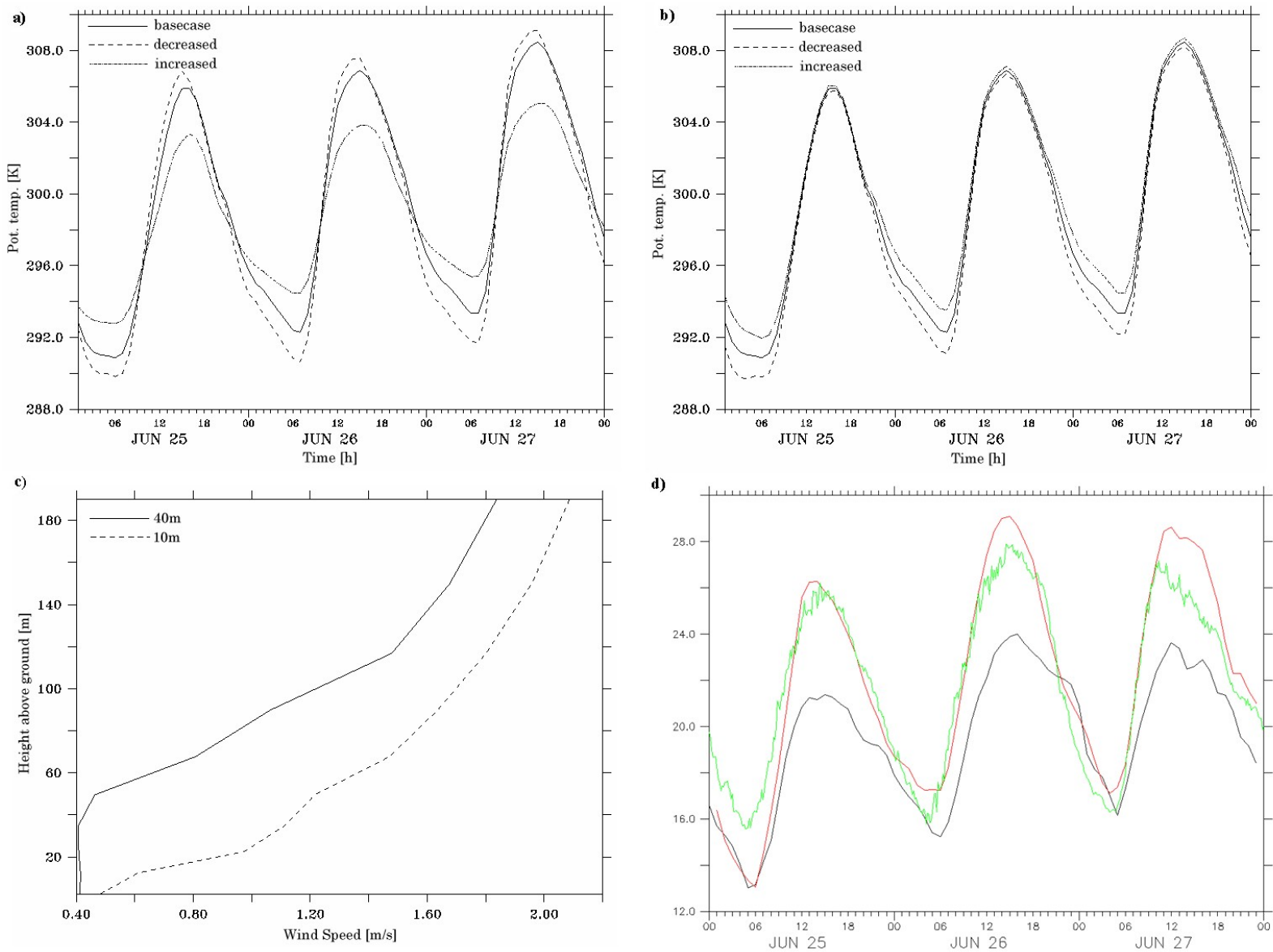

Fig. 7. Sensitivity and verifications results for the BEP module: (a) Potential temperature (in K) evolution during 25-27 June 2002 inside the urban canopy for three different street heat capacities: 1.4 (basecase), 14 (decreased), and 0.14 (increased) $\mathrm{MJm}^{-3} \mathrm{~K}^{-1}$; (b) Potential temperature (in K) evolution during 25-27 June 2002 inside the urban canopy for three different building indoor temperatures: 20 (basecase), 17 (decreased), and 23 (increased) ${ }^{\circ} \mathrm{C}$; (c) Simulated wind velocity profiles for building heights of 10 and $40 \mathrm{~m}$; (d) Air temperature evolution (in ${ }^{\circ} \mathrm{C}$ ) during 25-27 June 2002: measured (green line), simulated by LM model (blue line), and recalculated with BEP module (red line).

tion and infrared radiation). When the streets are much larger than the buildings, the buildings have almost no effects. The urban area acts then like a dry smooth ground: temperature is mainly influenced by the heat capacity, thermal diffusivity, albedo and emissivity of the streets (Fig. 7b).

When the width of the streets and buildings are comparable, the decrease of night temperature is attenuated. This can be due to two different effects. At first, the radiation trapping between building walls and streets stores the heat inside the urban canopy. Consequently, when buildings are high and streets are narrow the decrease of night temperature is low. Subsequently, during the day, the heat induced by the sun is always much higher than the energy coming from the buildings. During the night, however, the energy produced by the buildings can raise the temperature (if the building is heated). Consequently, variations in building indoor temperature affect the outdoor temperature only during the night (Fig. 7a).

\subsubsection{Verification versus the BUBBLE experiment}

The BEP-module was tested for the city of Basel (Switzerland) with experimental data from the BUBBLE experiment (Basel Urban Boundary Layer Experiment: Rotach et al., 2005). In a first step, the meteorological fields produced by the Local Model (LM) which is used by the Swiss meteorological institute (MeteoSwiss) as the aLMo version with a $7 \mathrm{~km} \times 7 \mathrm{~km}$ resolution, were interpolated onto a $1 \mathrm{~km} \times 1 \mathrm{~km}$ grid. In a second step, the meteorological fields were recomputed at the highest resolution solving the momentum, energy and turbulent kinetic energy budgets in the boundary layer and in the surface layer. The recomputed results were compared with the LM results and the data measured during BUBBLE. This comparison shows clearly that the module improves the simulated meteorological parameters. The urbanised parameterisation decreases wind velocity and increases temperature in the urban surface layer (Fig. 7d). 

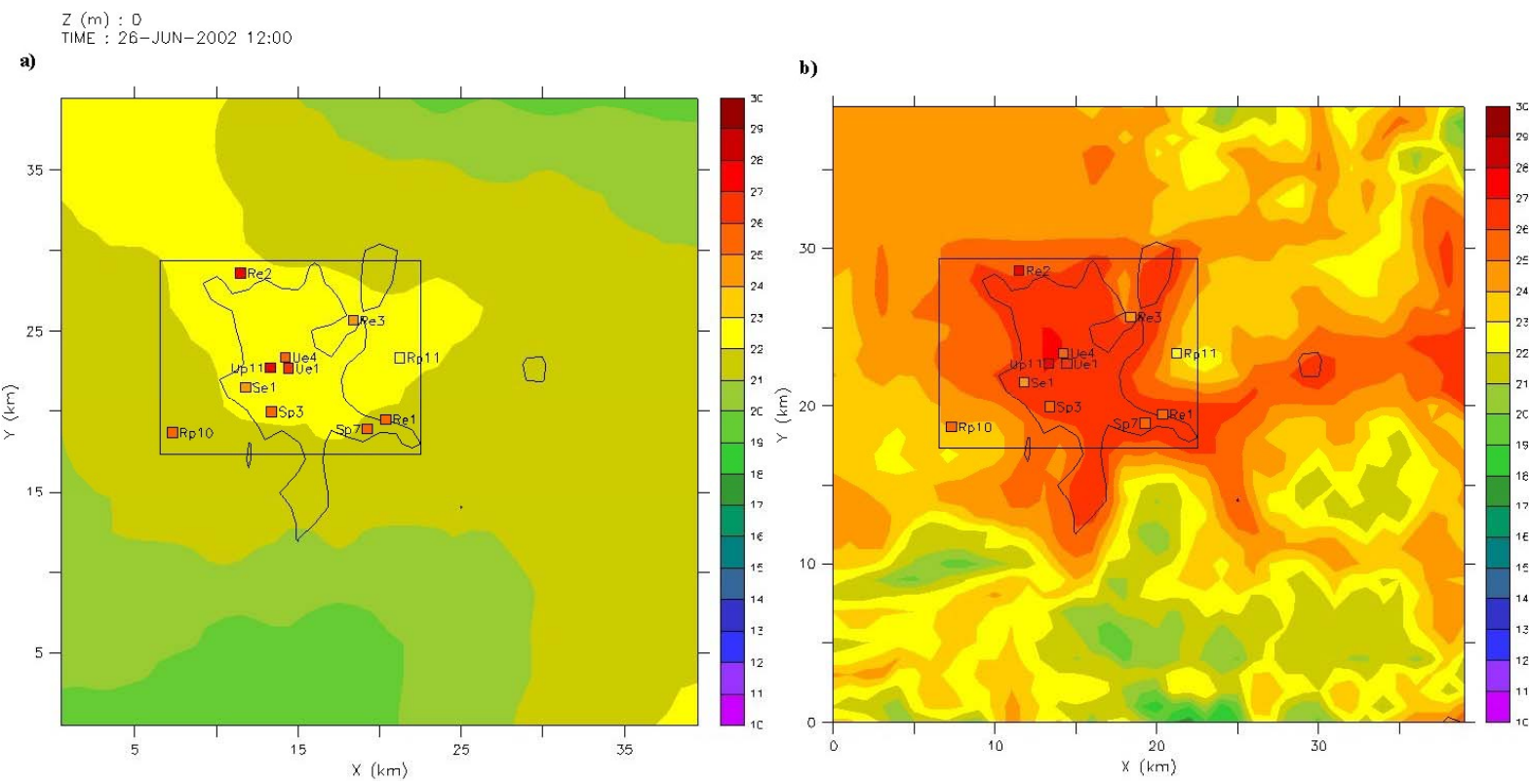

Fig. 8. Temperature fields over the Basel area at ground level at noon on 26 June 2002: (a) recalculated with BEP module and (b) interpolated from LM model (black line indicates the city boundaries; squares show the measured temperature at several sites).

During the day, the difference between the simulated results from LM and the recomputed results with the BEPmodule are larger than during the night. The LM clearly underestimates the temperature at all stations. The results obtained with the urban parameterisation are very close to the measurements in the city centre (stations Ue1 and Up11) while it slightly overestimates the temperature at the edge of the city (stations Se1, Sp3, Sp7, Re1) (Fig. 8).

The urban parameterisation developed by Martilli et al. (2002) shows a clear capacity to improve the results of NWP models (like LM or HIRLAM) by taking into account the effect of urban areas. However, the parameterisation should be further tested using different cities and longer periods.

4.4 Simulations involving urban soil layers with the submesoscale urbanised model SM2-U

The third module (Fig. 3) modified and tested for the urbanisation of mesometeorological models includes the detailed urban area soil submodel SM2-U (Sub-Mesoscales $S$ oil $M$ odel, $U$ rbanized version) module, developed by the ECN team (Dupont and Mestayer, 2006; Dupont et al., 2006).

\subsubsection{Model description}

The physical basis of the urban canopy model SM2-U was developed from the ISBA rural soil model of Noilhan and Planton (1989) with the inclusion of urban surfaces and the influence of buildings and sparse vegetation, while keeping the force-restore soil model approach. SM2-U has the ad- vantage of a unique model for both rural and urban soils that allows simulating continuously all districts of an urbanised area. The physical processes inside the urban canopy, such as heat exchanges, heat storage, radiative trapping, water interception, and surface water runoff, are integrated in a simple way. The only horizontal exchanges inside the urban canopy are radiation reflections and water runoff from saturated surfaces; the wind advection within the canopy layer is not considered. Under the surface, the sub-grid scale transfers are ensured in the two underlying continuous soil layers.

While for a natural soil partly covered with vegetation ISBA computes the budgets for the whole ground-vegetation system, SM2-U separates in each computational cell eight surface types (Fig. 9): for natural grounds, the bare soil without vegetation, noted "bare", the soil located between vegetation elements, "nat", and the vegetation cover "vegn"; for the anthropised areas, the building roofs, "roof", the paved surfaces without vegetation, "pav", the vegetation elements over a paved surface (e.g., road side trees), "vega", and the paved surface under the vegetation, "cova"; finally, the water surfaces, "wat". Each surface type is characterized by its area density $f_{i}$, with $\left(f_{i}\right)=1$, for $i \in\{$ bare, nat, pav, roof, vega, vegn, wat $\}$ in each grid cell and $f_{\text {vega }}=f_{\text {cova }}$.

SM2-U computes the water budget in three soil layers. A thin "surface layer" acts as a buffer for the evaporation and for the rain water transfer to/from the second soil layer. The second, root-influenced layer contains the available water for vegetation transpiration. The third, sub-root layer is a water reservoir introduced by Boone et al. (1999) in the ISBA-3L version. There is one surface layer for each surface type but one root and one sub-root layer cell per grid mesh 
(a)

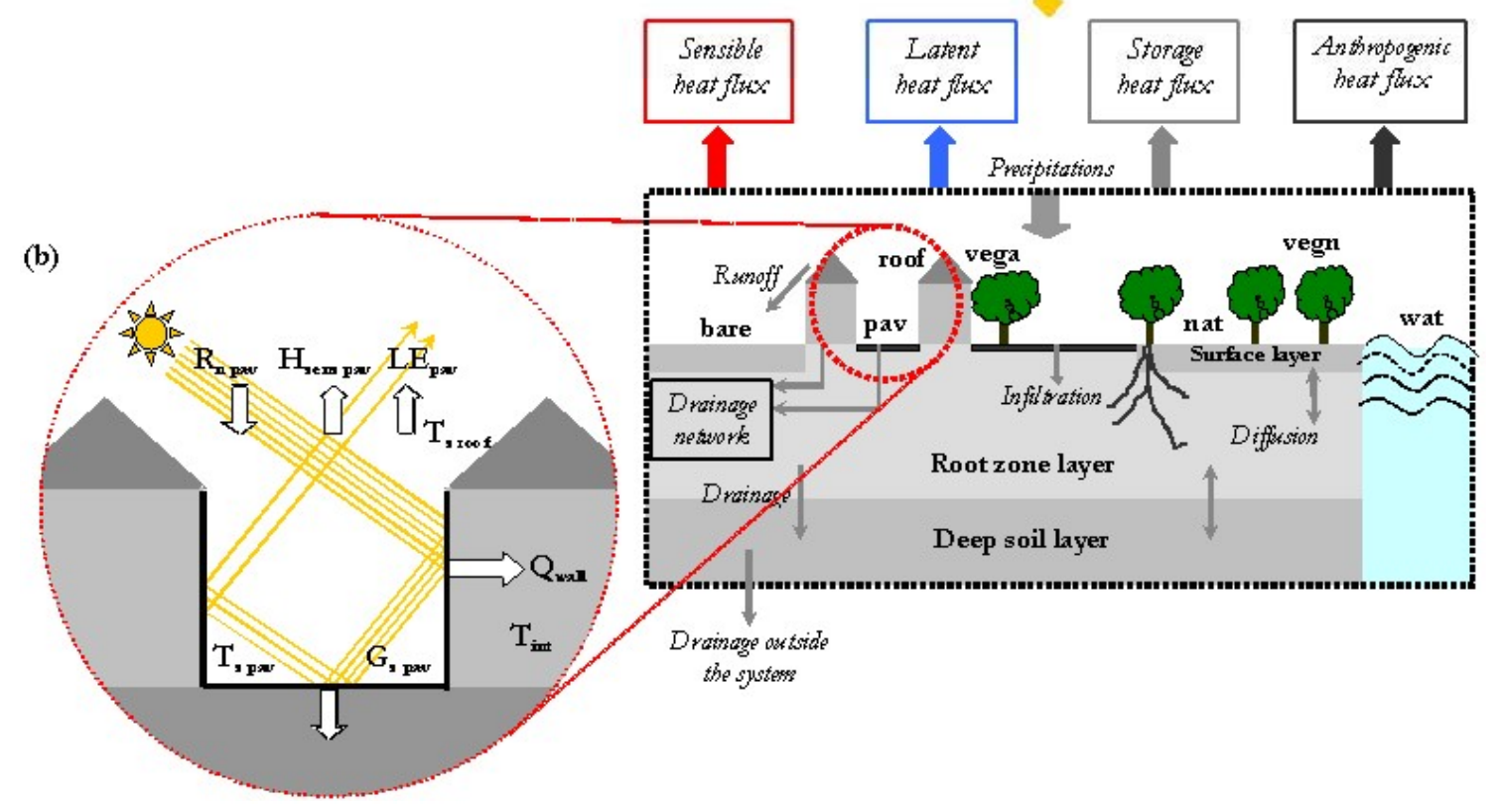

Fig. 9. Scheme of the SM2-U energy and water budget models: (a) with 7 surface types (bare soil without vegetation - "bare"; soil located between vegetation elements - "nat"; vegetation cover - "vegn"; building roofs - "roof"; paved surfaces without vegetation - "pav"; vegetation elements over a paved surface - "vega"; water surfaces - "wat") and 3 soil layers. (b) Energy budget of paved surfaces.

(Fig. 9). For vegetation, roofs, and paved surfaces an interception reservoir defines the maximum amount of retained liquid water. When the reservoir overflows the water runoff to the neighbour surface or to the draining network is computed explicitly (Dupont, 2001; Dupont et al., 2006). While roof surfaces are assumed fully impervious, paved surfaces are semi-impervious and let water infiltrate downwards but not upwards.

The energy budget is computed for each surface type in the cell:

$G_{s i}=Q *_{i}-H_{i}-L E_{i}$,

then the cell energy fluxes are obtained by averaging the individual fluxes weighted by the area density $f_{i} . Q *$ is obtained from the classical four-component radiation budget (Eq. 4). The storage heat flux in soil/building materials $G_{s}$ is computed as the residual of Eq. (8). To compute the aerodynamic heat fluxes $H_{i}$ and $L E_{i}$, SM2-U determines the temperature $T_{s i}$ and specific humidity $q_{v s i}$ of each surface type, and one deep soil temperature $T_{\text {soil }}$. The equations for the water vapour fluxes from vegetation and natural soils are identical to those of ISBA except that they use the surface type temperature instead of the average temperature. They are extended to the vegetation on paved surfaces. The water vapour fluxes from artificial surfaces are determined in the same way as from the vegetation, by extending the concept of the surface wet portion. Evaporation and sensible heat fluxes are computed using the resistance approach where the aerodynamic heat and humidity resistances depend on the wind velocity at the reference level and on the heat and water vapour transfer coefficients, respectively. The heat transfer coefficient is calculated following the non-iterative algorithm of Guilloteau (1998) for non-equal momentum and heat roughness lengths, $z_{0 m}$ and $z_{0 t}$ respectively. Guilloteau's method is based on a combination of Hogstrom's (1996) and Beljaars and Holtslag's (1991) formulations of the flux-profile relationships. It is inspired by Launiainen's (1995) method for stable stratification and generalises Byun's (1990) method for unstable stratification.

The humidity transfer coefficient is set equal to that of heat. The computed surface temperatures are assumed to be the skin temperatures, but not the aerodynamic temperatures at canopy top level. To solve the problem of inconsistency between skin and aerodynamic temperatures, the heat roughness length is not assumed equal to the momentum roughness length, using the Reynolds number-dependent formulation of Zilitinkevich (1995): $z_{0 t} / z_{0 m}=\exp \left(-\kappa C R e^{* 1 / 2}\right)$; with $C$ an empirical constant set to 0.1 as recommended by Chen et al. (1997). However, it is probable that the numerical value of $C$ should be revisited by a factor of ca. 10, since 
when compared to the model (Eq. 5) of Brutsaert and Sugita (1996) or Joffre (1988), which are close to each other, as $R e_{*}$ varies between typical value of $10^{2}$ to $10^{4}$, the Zilitinkevich model yields value of $\kappa B^{-1}=-\ln \left(z_{0 t} / z_{0 m}\right)$ between 0.1 and 4 , while the Brutsaert-Joffre version varies between 5 and 22 .

Bare soil water vapour fluxes depend on the relative humidity $q_{u i}$ at the ground surface and the surface temperature, while soil and vegetation heat capacity coefficients are, as in ISBA, dependent of the volumetric water content of the root zone layer; thus coupling the heat and water budgets. The natural surface temperature $T_{s i}$ is calculated by means of a force-restore equation:

$\partial T_{s i} / \partial t=C_{T s i} G_{s i}-(2 \pi / \tau)\left(T_{s i}-T_{\text {soil }}\right)$

for $i \in\{$ bare, nat, vega, vegn $\}$,

where $C_{T s i}$ is the inverse of the surface layer heat capacity and the parameter $\tau=86400 \mathrm{~s}$ is the day duration. Inversely the deep soil temperature is determined by a returnto-equilibrium equation towards the temperature average of all surfaces in contact with the soil. The time evolution of the surface layer water content $w_{i}$ is calculated with a similar force-restore equation.

The force-restore model does not apply to artificial surfaces because the thin surface materials respond rapidly to the environmental forcing while the underlying materials have insulating thermal properties, unlike natural soils. Normal heat conduction equations are used for these artificial covers, with two layers, a superficial layer which allows the model to respond quickly to the environmental forcing variations, and a second, inner layer which allows the artificial materials to store heat.

The 3D structure heterogeneity and complexity of the canopy make it impossible to compute explicitly all physical processes in operational simulations. Building walls are integrated with the paved surfaces into a street canyon energy budget (Fig. 9b). Thus, $T_{s \text { pav }}$ corresponds to an effective average temperature of street canyon surfaces. The building walls are accounted for in three ways: the heat flux through the walls; the heat storage capacity of walls; the radiative trapping inside the street.

The conduction heat fluxes between pavement layers integrate the walls by adding in parallel the heat fluxes through building wall layers, weighted by the wall-to-paved area ratio (in practice approximated by $2 \mathrm{H} / \mathrm{W}$ ). The heat fluxes through building walls are calculated in the same way as those through building roofs, with two layers and assuming a constant inner temperature.

The street canyon surface and second layer heat capacities $C_{T * \text { pav }}^{-1}$ are represented by two resistances in parallel for the walls $C_{T * \text { wall }}^{-1}$ and paved surfaces $C_{T * \text { floor }}^{-1}$ which depend on the wall/pavement layer thickness and volumetric thermal capacity: $C_{T * \text { pav }}^{-1}=C_{T * \text { wall }}^{-1} S_{\text {wall }} / S_{\text {pav }}+C_{T * \text { floor }}^{-1}$, where $S_{\text {wall }}$ and $S_{\mathrm{pav}}$ are, respectively, the total area of building walls and of paved surfaces in the cell.
The radiative trapping inside the street is modelled by introducing into the pavement radiation budget equation an effective albedo and effective emissivities, which depend on those of the street materials and on the canyon geometry. Based on Masson's (2000) calculations, these effective parameters have been related by Dupont and Mestayer (2006) to only one geometrical parameter, the street aspect ratio $H / W$.

\subsubsection{SM2-U model validation and sensitivity tests}

For a rural area, while ISBA determines only one surface temperature, SM2-U distinguishes vegetation $\left(T_{s \text { vegn }}\right)$ and bare soil $\left(T_{s}\right.$ nat $)$ surface temperatures. This modification in the original part of the model has been validated against the experimental data from HAPEX-MOBILHY and EFEDA campaigns (Dupont et al., 2006). The urban hydrological components of the model have been validated against the experimental data obtained during ten years at the Reze suburban site in the Nantes urban area (Berthier et al., 2006), with tests both on an annual scale and for stormy events (Dupont et al., 2006). Finally the energy budget urban parameterisations have been validated for a densely built city centre against the measurements of Grimmond et al. (2004) at the Marseilles central site during the campaign UBLESCOMPTE (Mestayer et al., 2005), in a forced mode without soil-atmosphere feedback, showing an excellent agreement on average (Dupont and Mestayer, 2006).

Based on these validation simulations, a series of additional simulations was performed to assess the impact on the heat fluxes of the wall parameterisations representing the canopy influence. At first the effective albedo and emissivities of the street canyon were replaced by those of the street canyon floor, i.e. asphalt properties. Most of the results were identical; the main impact is an increase in the root mean square difference between measurements and simulations but the averaged diurnal cycles are very similar (Dupont and Mestayer, 2006). The net radiation is slightly lower during the day due to the larger albedo ( 0.08 for the pavement and only 0.04 for the effective albedo at midday) while the replacement of the effective emissivities $(0.97$ and 0.99 , for the atmospheric absorption and infrared emission, respectively, in the basic simulations) by the asphalt emissivity (0.94) has little impact due to compensating influences. The further simulations differ either in aggregating the two layers of the artificial surfaces (roofs, walls and pavements) in only one layer with the same (averaged) transfer coefficients or in suppressing the walls. With one averaged layer the model does not reproduce well the early morning warming of the artificial surfaces because the layer is too thick, impeding the model fast response to environmental forcing variations; in the case when this unique layer has the same thickness as the first, surface layer of the base case the model does respond rapidly to the forcing variations but does not simulate well the amount of heat stored in the artificial materials, because 
the layer is too thin. Thus, two layers for representing artificial surfaces appear as a necessary compromise, whereby the first thin layer allows the model fast response, and the second layer ensures the storage capacity. When the walls are not simulated, the sensible heat fluxes are much less well simulated: the stored heat is smaller during the day, which results in a larger daytime sensible heat flux and a smaller nocturnal heat release inducing a negative nocturnal sensible heat flux.

After validation of the model with the Reze site measurements, alternative simulations in lighted the influence of the local water budget on the local climatology (only local effects may be demonstrated when the model is run in the stand-alone mode).

The mean surface temperature diurnal cycle in July 1996 for the reference simulation was analysed in Dupont et al. (2006) (Fig. 15). Four new simulations were run with only slight differences in the inputs and the resulting differences in the mean temperature cycle. All four runs simulate the suburban site behaviour as if 1996 had been a dry year (precipitation rates divided by 1000) while the weather remained otherwise unchanged (the general climatology of the French Atlantic coast around Nantes is very mild). Soil dryness is shown to neatly increase day-time surface temperatures, the difference exceeding $1.5^{\circ} \mathrm{C}$ between 9 a.m. and 4 p.m. (solid line). Observations of the energy budget components (not shown) show that, in the reference simulation the sensible and latent heat fluxes share equally about $85 \%$ of the net radiation (maximum $440 \mathrm{~W} / \mathrm{m}^{2}$ ), while the last $15 \%$ are stored in the ground during day-time. At night, the negative net radiation (ca. $40 \mathrm{~W} / \mathrm{m}^{2}$ ) is balanced by the storage heat release for two third and by a small negative sensible heat flux for one third. With the dry soil, the latent heat flux drops to about $12 \%$ of the net radiation while the storage heat flux remains unchanged and the sensible heat flux balances some $73 \%$ of the budget. The second alternative includes vegetation watering: every day between 7 a.m. and 8 p.m. water is poured at a rate of $1 \mathrm{~mm} / \mathrm{h}\left(1.45 \mathrm{~kg} \mathrm{~m}^{-2} \mathrm{~s}^{-1}\right)$ over the bare soil and $50 \%$ of the vegetation cover (figuring grass cover share). This moderate daily watering is shown to be sufficient for compensating the soil dryness influence on the local climate: the upper soil layer remains close to saturation and the energy budget cycle appears very similar to that of the reference case. Consequently the surface temperature is the same as in the reference case.

The last two simulations (Dupont et al., 2006, Fig. 15b) show the influence of realistic and antagonist layouts of the suburban settlement. In the case when the pavement of the road and parking lots is replaced by a stabilised grassy soil, which takes advantage of the evening watering to increase evapotranspiration, the mean temperature decreases $2^{\circ} \mathrm{C}$ more all day long, and even $2.5^{\circ} \mathrm{C}$ at midday. On the contrary, the covering of vegetated surfaces by pavement strongly increases day-time surface temperatures, up to $5.5^{\circ} \mathrm{C}$ around noon (i.e. a raise from 24 to $30^{\circ} \mathrm{C}$ ), without effect of the evening watering since the soil water does not percolate upwards through the pavement. In this last case the energy budget is largely perturbed since the heat storage is more than doubled, reaching $35 \%$ of the net radiation, while the sensible heat flux reaches $93 \%$ of the net radiation, the budget being balanced by a large negative latent heat flux due to the downward flux of water vapour to the dry surface.

The CPU computational expenses are rather high, e.g. for the SUBMESO model urbanised with SM2-U, one diurnal cycle run is equal approximately to $4.2 \mathrm{~h}$ on the NEC-SX6 supercomputer (on one processor). Realisation and tests of the SM2-U module in MM5 (Dupont et al., 2004) and HIRLAM (Baklanov et al., 2006b) models show that the computation CPU time is increasing up to 10 times in comparison with the original non-urbanised models (Baklanov, 2005). Further optimisation of the codes decreased the CPU time: up to 3 times - after optimisation of MM5u for multiprocessor supercomputers (Bornstein, 2007, personal communications), and in a few times for HIRLAM, urbanised by SM2-U, due to optimisation by calling SM2-U only for urban cells (with urban class $>5 \%$ )

\section{Conclusions and recommendations}

Different parameterisations of the urban sublayer for NWP models have been analysed and tested with different mesometeorological models. Several options for the integrated FUMAPEX urban module usable with NWP models have been suggested. The first version includes three main modules, which can be chosen depending on the specific problem, model resolution or city area:

1. Corrections of the surface roughness for urban areas and urban heat fluxes (adding the anthropogenic heat flux, heat storage capacity and albedo change). This can be complemented with an analytical model for wind velocity and diffusivity profiles inside the urban canopy (Zilitinkevich and Baklanov, 2005).

2. The urban sub-layer model BEP (Martilli et al., 2002; Hamdi and Schayes, 2007) with special physical parameterisations of the urban surface exchange for the urban sub-layer implemented into (or after) the NWP model.

3. The SM2-U full force-restore soil submodel for urban areas (Dupont and Mestayer, 2006; Dupont et al., 2006).

A fourth combined module, including all non-overlapping mechanisms from the SM2-U and BEP models, is under development.

It was shown that the implementation of the urban modules can significantly improve the forecasted meteorological fields for urban areas. The first module is the cheapest way of "urbanising" the model and can be easily implemented into operational NWP models as well as in Global/Regional 
Climate Models. The second module is a relatively more expensive (5-10\% computational time increase), but it gives a possibility to consider the energy budget components and fluxes inside the urban canopy. However, this approach is sensitive to the vertical resolution of NWP models and is not very effective if the first model level is higher than $30 \mathrm{~m}$. Therefore, an increase of the vertical resolution of current NWP models is required. The third module is considerably more expensive computationally ( $2-10$ times) than the first two modules. However, it provides the possibility to accurately study the urban soil and canopy energy exchange including the water budget. Therefore, the second and third modules are recommended for use in advanced urban-scale NWP and meso-meteorological research models. This will be demonstrated for NWP models in a forthcoming paper. The third module maybe very useful for implementation into research submeso-scale or micro-meteorological models (e.g., SUBMESO) for large eddy simulation or assessment (non-prognostic) studies. The first and second modules can be also implemented as urban interfaces or post-processors of NWP data for UAQ models.

Simulation results with these urban modules showed that the radiation budget does not differ significantly for urban vs. rural surfaces, as the increased loss of a net thermal longwave radiation is partly compensated by a gain in net shortwave radiation due to a lower albedo. The turbulent fluxes of sensible and latent heat, as well as their ratio are variable, depending in particular on the amount of rainfall that fell during the preceding period. Usually, the storage heat flux is significantly higher in urban areas compared to densely vegetated surfaces. This cannot be explained entirely by a higher thermal inertia, the heat conduction processes have different time scales in the soil (slow) and in wall (fast) materials - this makes the main difference. Other factors of importance are the low moisture availability and the extremely low roughness length for heat fluxes. The anthropogenic heat flux is the most typical urban energy component as it is absent over rural or natural surfaces.

One sophisticated way to simulate the storage heat flux for urban areas can be realised using the BEP (Sect. 4.3) or SM2$\mathrm{U}$ (Sect. 4.4) modules. One issue is to simplify the parameterisation of the storage heat flux in NWP model simulations for a few main types of urban areas and density of urban elements. Studies using these modules may give a possibility to derive a simplified classification of urban storage heat fluxes for specific urban classes to be used in NWP models.

As to further improvements in NWP and UAQ forecasting systems, the next step should be the intercomparisons of urban modules with(in) operational NWP models (for example, HIRLAM and LM) and their verification with respect to urban meteorological forecasts.

Urban canopy models are also suggested (and successfully tested for the BEP-module 2, see Sect. 4.3) to be implemented as an interface/post-processor module, separated from the NWP model. In this case, the urban sublayer model will be run separately, using NWP output data as a first approximation, and thus able to improve higher resolution meteorological fields close to and inside the urban canopy.

Such a novel approach has, of course, a clear drawback as it does not improve the meteorological forecast for the urban area and does not allow feedbacks. However, for urban air pollution modelling/forecasting and improvements of UAQ information and forecasting system, this approach can be very useful and easier to realise, because it does not require any modifications of the operational NWP model (which are usually very difficult and time consuming). This approach thus considers the urban sublayer models (together with several upper layers and surrounded areas) as interface modules between the NWP and UAQ models.

The current versions of the considered urban modules have several shortcomings and have to be improved and further developed. For the first approach (module 1), the complemented analytical model for wind velocity and diffusivity profiles inside the urban canopy (Zilitinkevich and Baklanov, 2005) has to be tested with different NWP models and meteorological preprocessors, and carefully verified against experimental data for different regimes. Besides, it is advisable to extend this model for temperature and humidity profiles. The current version of the second module (BEP) does not consider the moisture and latent heat fluxes and does not completely incorporate the anthropogenic heat flux. Therefore, these should be included into a new version of the BEP module. Besides, recalculation of accessible meteorological fields in the lowest sublayers is necessary. The third module (SM2-U) needs further development considering the building drag effect (it will be realised in module 4), whereas snow and ice have to be included for NWP during winter periods, especially for northern areas. The existing version of this module, when run for every grid-cell, is too expensive for operational NWP models, therefore the module has to be optimised by making calculations only for the urban cells.

It is obvious that these developments in process parameterisations and model resolution require more and more adequate data for validating, improving and initialising NWP or meso-meteorological models. There is a need for carrying out urban field campaigns in the future to provide data from which insights may be gained in order to devise simpler models and parameterizations for complex models. The existing measurements have limitations which arise due to inescapable constraints on field programmes in cities, including:

- Availability of suitable and representative instrument sites, allowing for security, power, data transmissions, neighbourhood convenience, public safety, accessibility, and planning permission;

- Height and positioning of sensors to meet the needs of the researchers, such as adequate reference height, so that the appropriate surface type is within the upwind fetch and observational foot-print for sensors; 
- Duration of instrument deployment and data sampling rates during the campaign, as few campaigns can be long term, yet measurements are needed in all seasons;

- Sufficient number of sensors to be deployed within the city area as well as at a number of reference rural sites so that influences due to the city can be differentiated from the daily and diurnal changes under various prevailing meteorological situations.

There is a real need for long measurement runs, so that a variety of conditions are sampled, and that instrumental techniques can be compared against each other. Potential of remote sensing methodologies and satellite observations should also be better exploited.

Improved urban meteorological forecasts will also provide better information to city management regarding UAQ and on hazardous compounds or other urban stressors, e.g. urban runoff and flooding, icing and snow accumulation, high urban winds or gusts, heat or cold stress in growing cities and/or a warming climate. Moreover, the availability of reliable urban scale weather forecasts could be a relevant support for the emergency management of fires, accidental toxic emissions, potential terrorist actions, etc.

\section{Appendix A Acronyms of partners}

\begin{tabular}{|c|c|}
\hline rianet: & $\begin{array}{l}\text { Environmental consulting company ARI } \\
\text { ANET s.r.l, Milan, Italy }\end{array}$ \\
\hline CEAM: & $\begin{array}{l}\text { The Mediterranean Centre for Environ } \\
\text { mental Studies Foundation, Valencia } \\
\text { Spain }\end{array}$ \\
\hline CORIA: & $\begin{array}{l}\text { COmplexe de Recherche Interprofessio } \\
\text { nel en Aérothermochimie, Université } \\
\text { Rouen, France }\end{array}$ \\
\hline DMI: & $\begin{array}{l}\text { Danish Meteorological Institute, } \\
\text { Copenhagen, Denmark }\end{array}$ \\
\hline DWD: & $\begin{array}{l}\text { German Weather Service, Offenbach, } \\
\text { Germany }\end{array}$ \\
\hline ECN: & Ecole Centrale de Nantes, Nantes, Fran \\
\hline $\begin{array}{l}\text { EPA Emilia- } \\
\text { Romagna: }\end{array}$ & $\begin{array}{l}\text { Environmental Protection Agency of } \\
\text { region Emilia-Romagna, Bologna, Italy }\end{array}$ \\
\hline EPFL: & $\begin{array}{l}\text { Ecole Polytechnique Fédérale de } \\
\text { Lausanne, Switzerland }\end{array}$ \\
\hline EPHYSE: & $\begin{array}{l}\text { Institut National de la Recherche } \\
\text { Agronomique, Bordeaux, France }\end{array}$ \\
\hline GREYC: & $\begin{array}{l}\text { Groupe de REcherche en Informatiqu } \\
\text { Image, Automatique et Instrumentation } \\
\text { Caen, France }\end{array}$ \\
\hline MeteoSwiss: & National Weather Service of Switzerland \\
\hline Met.no: & $\begin{array}{l}\text { Norwegian Meteorological Institute, Oslc } \\
\text { Norway }\end{array}$ \\
\hline UCL: & $\begin{array}{l}\text { Universit e Catholique de Louvain, } \\
\text { Belgium }\end{array}$ \\
\hline
\end{tabular}

Acknowledgements. The authors are grateful to L. Laursen, B. Amstrup, C. Petersen, A. Rasmussen, K. Sattler (DMI), S. Leroyer, I. Calmet (ECN), N. Long (GREYC), S. Dupont (EPHYSE), M. Piringer (ZAMG), G. Schayes (UCL), B. Fay (DWD), M. Rotach (MeteoSwiss), R. Sokhi (UH), S. Finardi (Arianet), A. Martilli (CIEMAT) and many other FUMAPEX and COST 715 partners for collaboration, discussions and constructive comments. Financial support of this study came from EU FUMAPEX (EVK4-CT-200200097) project.

Edited by: S. Galmarini

\section{References}

Arnfield, A. J. and Grimmond, C. S. B.: An urban canyon energy budget model and its application to urban storage heat flux modelling, Energy and Buildings, 27, 61-68, 1998.

Arya S. P. S.: Buoyancy effects in a horizontal flat-plate boundary layer, J. Fluid Mech., 68, 321-343, 1975.

Baklanov, A., Hänninen, O., Slørdal, L. H., Kukkonen, J., Sørensen, J. H., Bjergene, N., Fay, B., Finardi, S., Hoe, S. C., Jantunen, M., Karppinen, A., Rasmussen, A., Skouloudis, A., Sokhi, R. S., and Ødegaard, V.: Integrated systems for forecasting urban meteorology, air ollution and population exposure, Atmos. Chem. Phys., 7, 855-874, 2006a.

Baklanov, A., Mahura, A., Nielsen, N. W., and Petersen, C. Approaches for urbanization of DMI-HIRLAM NWP model, HIRLAM Newsletter, 49, 61-75, 2006 b.

Baklanov, A., Mahura, A., Petersen, C., Sattler, K., and Nielsen, N. W.: Effects of Urbanized Areas for NWP DMI-HIRLAM High Resolution Model Operational Runs, Journal of Computing Technologies, 11(1), 157-167, 2006c.

Baklanov, A., Rasmussen, A., Fay, B., Berge, E., and Finardi, S.: Potential and shortcomings of numerical weather prediction models in providing meteorological data for urban air pollution forecasting, Water, Air Soil Poll. Focus, 2, 43-60, 2002.

Baklanov, A. (Ed.): Integrated and validated NWP systems incorporating urban improvements, FUMAPEX M4.4 Report, Danish Meteorological Institute, Copenhagen, 136 pp., available from: http://fumapex.dmi.dk, 2005.

Belcher, S. E. and Coceal, O.: Scaling the urban boundary layer, in COST Action 715 Workshop on Urban Boundary Layer Parameterisations (Zurich, 24-25 May 2001), edited by: Rotach, M., Fisher, B., and Piringer, M., Office for Official Publications of the European Communities, EUR 20355, 7-16, 2002.

Belcher, S. E., Jerram, N., and Hunt, J. C. R.: Adjustment of the turbulent boundary layer to a canopy of roughness elements, J. Fluid Mech., 488, 369-398, 2003.

Beljaars, A. C. M. and Holtslag, A. A. M.: Flux Parameterization over Land Surfaces for Atmospheric Models, J. Appl. Meteorol., 30, 327-341, 1991.

Berge, E., Walker, S.-E., Sorteberg, A., Lenkopane, M., Eastwood, S., Jablonska, H. I., and Køltzow, M. Ø.: A real-time operational forecast model for meteorology and air quality during peak air pollution episodes in Oslo, Norway, Water, Air Soil Poll. Focus, 2, 745-757, 2002.

Berthier, E., Dupont, S., Mestayer, P. G., and Andrieu, H.,: Comparison of two evapotranspiration schemes on a-sub- urban site, J. Hydrol., 328, 635-646, 2006. 
Boone, A., Calvet, J. C., and Noilhan, J.: Inclusion of a Third Soil Layer in a Land Surface Scheme using the Force-Restore Method, J. Appl. Meteorol., 38, 1611-1630, 1999.

Bottema, M.: Urban roughness modelling in relation to pollutant dispersion, Atmos. Environ., 31, 3059-3075, 1997.

Bottema, M. and Mestayer, P. G.: Urban roughness mapping - validation techniques and some first results, J. Wind Engineering \& Industrial Aerodynamics, 74-76, 163-173, 1998.

Brutsaert, W.: The roughness length for water vapor, sensible heat, and other scalars, J. Atmos. Sci., 32, 2028-2031, 1975.

Brutsaert, W. and Sugita, M.: Sensible heat transfer parameterisation for surfaces with anisothermal dense vegetation, J. Atmos. Sci., 53, 209-216, 1996.

Byun, D. W.: On the Analytical Solutions of Flux-Profile Relationships for the Atmospheric Surface Layer, J. Appl. Meteorol., 29, 652-657, 1990.

Chen, F., Janjic, Z., and Mitchell, K.: Impact of atmospheric surface-layer parameterizations in the new land-surface scheme of the NCEP mesoscale ETA model, Bound.-Lay. Meteorol., 85, 391-421, 1997.

Clarke, J. A.: Energy simulation in building design, Adam Hilger, Bristol, 1985.

Davenport, A., Grimmond, S., Oke, T., and Wieringa, J.: The revised Davenport roughness classification for cities and sheltered country, 3rd Symp. On the Urban Environment, 14-18 Aug. 2000, Davis, Ca, AMS Proceedings, 9-10, 2000.

Doms, G. and Sch" attler, U.: The nonhydrostatic limited-area model LM, part1: scientific documentation, R\&D Dep. of DWD, 169 pp., 1999.

Dupont, S.: Modelisation Dynamique et Thermodynamique de la Canopee Urbaine: Realisation du Modèle de Sols Urbains pour SUBMESO, Doctoral thesis, Université de Nantes, France, 2001.

Dupont, S., Otte, T. L., and Ching, J. K. S.: Simulation of meteorological fields within and above urban and rural canopies with a mesoscale model (MM5), Bound.-Lay. Meteorol., 113, 111-158, 2004.

Dupont, S., and Mestayer, P. G.: Parameterization of the urban energy budget with the submesoscale soil model, J. Appl. Meteorol. Climatol., 45, 1744-1765, 2006.

Dupont, S., Mestayer, P. G., Guilloteau, E., Berthier, E., and Andrieu, H.: Parameterisation of the Urban Water Budget with the Submesoscale Soil Model (SM2-U), J. Appl. Meteorol. Climatol., 45, 624-648, 2006.

Ellefsen, R.: Mapping and measuring buildings in the canopy boundary layer in ten U.S. cities, Energ. Buildings, 15-16(3-4), 1025-1049, 1991.

Fay, B. and Neunhauserer, L.: Evaluation of high-resolution forecasts with the non-hydrostaticnumerical weather prediction model Lokalmodell for urban air pollutionepisodes in Helsinki, Oslo and Valencia, Atmos. Chem. Phys., 6, 2107-2128, 2006

Fay, B., Neunhauserer, L., Palau, J. L., Perez-Landa, G., Dieguez, J. J., Ødegaard, V., Bonafe, G., Jongen, S., Rasmussen, A., Amstrup, B., Baklanov, A., and Damrath, U.: Evaluation and intercomparison of operational mesoscale models for FUMAPEX target cities, FUMAPEX Report for D3.4, DWD Offenbach, Germany, June 2005, 110 pp., 2005.

Fehrenbach, U., Scherer, D., and Parlow, E.: Automated classification of planning objectives for the consideration of climate and air quality in urban and regional planning for the example of the region of Basel/Switzerland, Atmos. Environ., 35(32), 5605$5615,2001$.

Fisher, B., Joffre, S., Kukkonen, J., Piringer, M., Rotach, M., and Schatzmann, M. (Eds.): COST-715 "Meteorology applied to urban air pollution problems", Final Report, CEC Publication EUR, Luxembourg, in print, 2005.

Fisher, B., Kukkonen, J., Piringer, M., Rotach, M., and Schatzmann, M.: Meteorology applied to urban air pollution problems: concepts from COST 715, Atmos. Chem. Phys., 6, 555-564, 2006, http://www.atmos-chem-phys.net/6/555/2006/.

Gastellu-Etchegorry, J. P., Martin, E., and Gascon, F.: DART: a 3-D model for simulating satellite images and surface radiation budget, Int. J. Remote Sensing, 25(1), 73-96, 2004.

Grell, G., Dudhia, J., and Stauer, D.: A Description of the FifthGeneration PENN STATE/NCAR Mesoscale Model (MM5), NCAR Technical Note, NCAR/TN-398+STR, Boulder, Colorado, National Center for Atmospheric Research, 138 pp., 1994.

Grimmond, C. S. B., Cleugh, H. A., and Oke, T. R.: An objective urban heat storage model and its comparison with other schemes, Atmos. Environ., 25B, 311-326, 1991.

Grimmond, C. S. B. and Oke, T. R.: Heat storage in urban areas: Local-scale observations and evaluation of a simple model, J. Appl. Meteorol., 38, 922-940, 1999a.

Grimmond, C. S. B. and Oke, T. R.: Aerodynamic properties of urban areas derived from analysis of surface form, J. Appl. Meteorol., 38(9), 1262-1292, 1999b.

Grimmond, C. S. B., Salmond, J. A., Oke, T. R., Offerle, B., and Lemonsu, A.: Flux and turbulence measurements at a densely built-up site in Marseille: Heat, mass (water and carbon dioxide), and momentum, J. Geophys. Res., 109, D24101, doi:10.1029/2004JD004936, 2004.

Groleau, D., Fragnaud, F., and Rosant, J. M.: Simulation of the radiative behaviour of an urban quarter of Marseille with the Solene model, Fifth International Conference on Urban Climate, Lodz, Pologne, 1-5 September, 2003.

Guilloteau, E.: Optimized Computation of Transfer Coefficients in Surface Layer with Different Momentum and Heat Roughness Lengths, Bound.-Lay. Meteorol., 87, 147-160, 1998.

Hogstrom, U.: Review of Some Basic Characteristics of the Atmosphere Surface Layer, Bound.-Lay. Meteorol., 78, 215-246, 1996.

Hamdi, M. and Schayes, G.: Validation of Martilli's urban boundary layer scheme with measurements from two mid-latitude European cities, Atmos. Chem. Phys., 7, 4513-4526, 2007, http://www.atmos-chem-phys.net/7/4513/2007/.

Hasager, C. B., Nielsen, N. W., Boegh, E., Jensen, N. O., Christensen, J. H., Dellwik, E., and Soegaard, H.: Effective roughnesses calculated from satellite-derived land cover maps and hedge information and used in a weather forecasting model, Bound.-Lay. Meteorol., 109, 227-254, 2003.

Joffre, S. M.: Momentum and Heat Transfers in the Surface Layer over a Frozen Sea, Bound.-Lay. Meteorol., 24, 211-229, 1982.

Joffre, S. M.: Modelling the Dry Deposition Velocity of Highly Soluble Gases to the Sea Surface, Atmos. Environ., 22(6), 11371146, 1988.

Kusaka, H., Kondo, H., Kikegawa, Y., and Kimura, F.: A Simple Single-Layer Urban Canopy Model for Atmospheric Models: Comparison with Multi-Layer and SLAB Models, Bound.-Lay. Meteorol., 101, 329-358, 2001. 
Lagouarde, J.-P., Moreau, P., Solliec, F., Groleau, D., Irvine, M., Bonnefond, J.-M., and Voogt, J.: Etude experimentale et modelisation des effets directionnels dans l'IRT en zone urbaine, Atelier de Modelisation de l'Atmosphere 2002, Meteo France, Toulouse, 17-19 Dec 2002, 111-114, 2002.

Launiainen, J.: Derivation of the Relationship between the Obukhov Stability Parameter and the Bulk Richardson Number for FluxProfile Studies, Bound.-Lay. Meteorol., 76, 165-179, 1995.

Long, N.: Analyses morphologiques et aerodynamiques du tissu urbain - Application a la climatologie urbaine de Marseille pendant la campagne ESCOMPTE, Doctoral Thesis, Universite des Sciences et Techniques de Lille, Dec 2003, 297 pp., 2003 (in French).

Long, N. and Kergomard, C.: Classification morphologique du tissus urbain pour des applications climatologiques; Cas de Marseille, Revue Internationale de Géomatique, 15, 487-512, 2005.

Long, N., Mestayer, P. G., and Kergomard, C.: Development of a software to describe the city morphology and to compute aerodynamic parameters from an urban data base. Proceedings of the 4th symposium on Urban Climatology, American Meteorological Society, 20-24 May 2002, Norfolk, 31-32, 2002.

Louis, J. F.: A parametric model of vertical eddies fluxes in the atmosphere, Bound.-Lay. Meteorol., 17, 187-202, 1979.

Mahura, A., Baklanov, A., Petersen, C., Sattler, K., Amstrup, B., and Nielsen, N. W.: ISBA Scheme Performance in High Resolution Modelling for Low Winds Conditions, HIRLAM Newsletter, 49, 22-35, 2006.

Mahura, A., Leroyer, S., Mestayer, P., Calmet, I., Dupont, S., Long, N., Baklanov, A., Petersen, C., Sattler, K., and Nielsen, N. W.: Large eddy simulation of urban features for Copenhagen metropolitan area, Atmos. Chem. Phys. Discuss., 5, 11183 $11213,2005$.

Martilli, A., Clappier, A., and Rotach, M. W.: An Urban Surface Exchange Parameterisation for Mesoscale Models, Bound.-Lay. Meteorol., 104, 261-304, 2002.

Masson, V.: A Physically-Based Scheme for the Urban Energy Budget in Atmospheric Models, Bound.-Lay. Meteorol., 98, 357-397, 2000.

Mestayer, P. and Bottema, M.: Parameterisation for roughness parameters in urban areas, in: COST Action 715 Workshop on Urban Boundary Layer Parameterisations (Zurich, 24-25 May 2001), edited by: Rotach, M., Fisher, B., and Piringer, M., Office for Official Publications of the European Communities, EUR 20355, 51-61, 2002.

Mestayer, P. G., Durand, P., Augustin, P., Bastin, S., Bonnefond, J.-M., B'enech, B., Campistron, B., Coppalle, A., Delbarre, H., Dousset, B., Drobinski, P., Druilhet, A., Frejafon, E., Grimmond, S., Groleau, D., Irvine, M., Kergomard, C., Kermadi, S., Lagouarde, J.-P., Lemonsu, A., Lohou, F., Long, N., Masson, V., Moppert, C., Noilhan, J., Offerle, B., Oke, T., Pigeon, G., Puygrenier, V., Roberts, S., Rosant, J.-M., Said, F., Salmond, J., Talbaut, M., and Voogt, J.: The Urban Boundary Layer Field Experiment over Marseille, UBL/CLU-ESCOMPTE: Experimental Set-up and First Results, Bound.-Lay. Meteorol., 114, 315-365, 2005.

NASA: Earth at Night, http://antwrp.gsfc.nasa.gov/apod/ap001127. html, 2000.

Neunhauserer, L., Fay, B., Baklanov, A., Bjergene, N., Kukkonen, J., Ødegaard, V., Palau, J. L., Perez Landa, G., Rantamaki, M.,
Rasmussen, A., and Valkama, I.: Evaluation and comparison of operational NWP and mesoscale meteorological models for forecasting urban air pollution episodes - Helsinki case study, in: Proceedings of the 9th International Conference on Harmonisation within Atmospheric Dispersion Modelling for Regulatory Purposes, edited by: Suppan, P., 1-4 June 2004, GarmischPartenkirchen, Germany, Vol. 2, 245-249, 2004.

Noilhan, J. and Planton, S.: A Simple Parametrization of Land Surface Processes for Meteorological Models, Mon. Weather Rev., 117, 536-549, 1989.

Oke, T. R.: Boundary layer climates, London, Methuen \& Co Ltd, J. Wiley \& Sons, New York, 1978.

Oke, T. R., Spronken-Smith, R., Jauregui, E., and Grimmond, C. S. B.: Recent energy balance observations in Mexico City, Atmos. Environ., 33, 3919-3930, 1999.

Otte, T. L., A. Lacser, S. Dupont, and J. K. S. Ching: Implementation of an urban canopy parameterization in a mesoscale meteorological model, J. Appl. Meteor., 43, 1648-1665, 2004.

Pigeon, G., Durand, P., and Masson, V.: Quantification of anthropogenic heat releases over Toulouse (France) during the CAPITOUL field program, Short Papers of the 5th International Conference on Urban Air Quality Valencia, Spain, 29-31 March, 2005.

Piringer, M. and Joffre, S. (Eds.): The urban surface energy budget and mixing height in European cities: Data, models and challenges for urban meteorology and air quality, Baklanov, A., Burzynski, J., Christen, A., Deserti, M., De Ridder, K., Emeis, S., Joffre, S., Karppinen, A., Mestayer, P., Middleton, D., Piringer, M., and Tombrou, M. (co-authors), Final Report of WG2 COST Action 715, 194 pp., 2005.

Rotach, M. W.: Determination of the zero-plane displacement in an urban area, Bound.-Lay. Metorol., 67, 187-193, 1994.

Rotach, M. W.: On the influence of the urban roughness sublayer on turbulence and dispersion, Atmos. Environ., 33, 4001-4008, 1999.

Rotach, M. W., Vogt, R., Bernhofer, C., Batchvarova, E., Christen, A., Clappier, A., Feddersen, B., Gryning, S.-E., Mayer, H., Mitev, V., Oke, T. R., Parlow, E., Richner, H., Roth, M., Roulet, Y.-A., Ruffieux, D., Salmond, J., Schatzmann, M., and Voogt, J. A.: BUBBLE - an Urban Boundary Layer Project, Theoretical Appl. Climatol., 81(3-4), 231-261, doi:10.1007/s00704-0040117-9, 2005.

Sass, B., Nielsen, N. W., Jørgensen, J. U., Amstrup, B., Kmit, M., and Mogensen, K. S.: The operational DMI-HIRLAM system 2002-version, DMI Technical Report 02-05, 60 pp., 2002.

Soux, A., Voogt, J. A., and Oke, T. R.: A model to calculate what a remote sensor 'sees' of an urban surface, Bound.-Lay. Meteorol., 111, 109-132, 2004.

Wood, N. and Mason, P.: The Influence of Static Stability on the Effective Roughness Lengths for Momentum and Heat Transfer, Q. J. Roy. Meteor. Soc., 117, 1025-1056, 1991.

Zilitinkevich, S. S.: Dynamics of the Atmospheric Boundary Layer, Gidrometizdat, Leningrad, USSR, 1970 (in Russian).

Zilitinkevich, S. S.: Non-Local Turbulent Transport: Pollution Dispersion Aspects of Coherent Structure of Convective Flows, in: Air Pollution III - Volume I. Air Pollution Theory and Simulation, edited by: Power, H., Moussiopoulos, N., and Brebbia, C. A., Computational Mechanics Publications, Southampton, Boston, 53-60, 1995. 
Zilitinkevich, S. and Baklanov, A.: An analytical model of the mean-wind and the momentum flux profiles in the urban roughness layer, in: DMI Scientific Report \#04-08, ISBN 87-7478510-9, Chap. 3, 42-46, 2005.

Zilitinkevich, S. S., Baklanov, A. A., Mammarella, I., Joffre, S. M.: The effect of stratification on the surface resistance for very rough vegetated and urban surfaces, in: 6th International Conference on Urban Climate, June 12-16, 2006, Goteborg, Sweden, ISBN-10:91-613-9000-1, 415-418, 2006a.
Zilitinkevich, S. S., Hunt, J. C. R., Grachev, A. A., Esau, I. N., Lalas, D. P., Akylas, E., Tombrou, M., Fairall, C. W., Fernando, H. J. S., Baklanov, A., and Joffre, S. M.: The influence of large convective eddies on the surface layer turbulence, Q. J. Roy. Meteor. Soc., 132, 1423-1456, 2006b. 